\title{
Una aproximación teórica a la obra de Arturo Valencia Zea De la posesión y la función social de la propiedad: el gran problema jurídico del siglo xx en Colombia, revisión histórico jurídica*
}

Guillermo Castro Ayala**

"Die Philosophen haben die Welt nur verschieden interpretiert; es kommt aber darauf an, sie zu verändern".

Karl Marx, Thesen über Feuerbach, Fassung von, 1888

Recepción: 8 de junio de 2017

Aprobación: 10 de octubre de 2017

\begin{abstract}
"Al historiador que quiera revivir una época, Fustel de Coulanges le recomienda que se quite de la cabeza todo lo que sabe del curso sucesivo de la historia. No se podría definir mejor el procedimiento mediante el cual el materialismo histórico ha roto los puentes. Es un procedimiento de compenetración. Su origen es la negligencia del corazón, la acedía, que desespera de adueñarse de la imagen histórica auténtica, que relampaguea un instante. Los teólogos medievales la consideraban el fundamento de
\end{abstract}

* Esta investigación fue patrocinada por el DAAD [Deutsche Akademische Austausch Dienst] o Servicio de Intercambio Académico Alemán y la cátedra del prof. Martín Ibler, de Derecho Público de la Universidad de Konstanz, a través de la financiación de un periodo de investigación posdoctoral de diciembre de 2013 a enero de 2014 en la Universidad de Konstanz, Baden Württemberg, en la República Federal de Alemania y en la ciudad de París, Francia. El presente es producto de investigación del proyecto: "Constitucionalización del Derecho Privado", del Grupo Geppi de la Universidad Católica de Colombia, 2014-2015. DOI: http://dx.doi.org/10.15332/ s1909-0528.2018.0001.01

** Profesor asociado, Universidad Nacional de Colombia; Jurist Magister (Universidad Nacional de Colombia); Magister Llegum (Ll.M.), cum laude (Universität Konstanz - Alemania); Doktor Juris, magna cum laude (Universität Konstanz - Alemania). Director de Investigaciones en Derecho Privado, Grupo Geppi, Universidad Católica de Colombia. jgcastroa@unal.edu.co; jose.castro-ayala@uni-konstanz.de 
la tristeza. Flaubert que la había conocido escribió: 'peu de gens devineront combien il a fallu être triste por ressusciter Carthage'. La naturaleza de esta tristeza se esclarece cuando se pregunta con quién se compenetra el historiador historicista. La respuesta suena inevitable: con el vencedor. Pero los amos eventuales son los herederos de todos aquellos que han vencido. Por consiguiente, la compenetración con el vencedor resulta clave ventajosa para el amo del momento. Con lo cual se ha dicho suficiente respecto al materialismo histórico. Quien quiera haya conducido la victoria hasta el día de hoy, participa en el cortejo triunfal en el cual los dominadores de hoy pasan sobre aquellos que hoy yacen en tierra".

Séptima tesis de filosofía de la historia, en Ensayos escogidos

(Benjamin, 1999, p. 45)

\section{RESUMEN}

El presente manuscrito pretende contextualizar las nociones de posesión y propiedad desde una metodología de investigación cualitativa y de conformidad con método de investigación histórico-jurídico. Para efectos de lo anterior, el análisis parte de la Doctrina planteada por el profesor Arturo valencia Zea, quien analiza la doctrina europea, para analizar la naturaleza jurídica de las instituciones jurídicas referenciadas, aspectos que se pretenden describir en el presente manuscrito.

Palabras clave: Propiedad, posesión, Ley, Constitución

\section{Abstract}

The present manuscript aims to contextualize the notion of possession and ownership from a qualitative research methodology and in accordance with historical-juridical research method. For the purposes of the above, the analysis is based on the doctrine proposed by Professor Arturo Valencia Zea, who analyzes the European Doctrine, to analyze the legal nature of the referenced legal institutions, aspects that are intended to be described in this manuscript.

Key words: property, possession, law, Constitution. 


\section{INTRODUCCIÓN}

Se cumplen cien años del nacimiento del tratadista de derecho civil colombiano Arturo Valencia Zea, en el municipio de Bojacá. Probablemente el único escritor que ha agotado la dogmática del derecho civil colombiano, el derecho comercial, el régimen de tierras, las instituciones familiares y muchos otros temas asociados a la comprensión privatista. Desde mi ingreso al pregrado de Derecho en esta facultad, conozco el trabajo de Valencia Zea y mi formación ha estado estrechamente ligada a la lectura crítica de su obra ${ }^{1}$.

1 He de confesar también que a pesar de no haber alcanzado a tener el honor de visitar sus clases, conozco a Valencia Zea de pasillos y de cafés, de tribunales y de Cortes, de teorías y de acaloradas discusiones con amigos y colegas, de conferencias y de insospechadas consultadas y verificadas certezas que me llevaron a modificar desde una palabra, hasta una demanda, una providencia judicial o incluso una clase entera; pero, por sobre todo, como lo he mencionado, conozco a Valencia Zea por la relectura jurídica más completa, perenne y trashumante que de dogmático alguno del derecho yo haya realizado.

Desde el inicio de las clases de Parte General y Personas, impartidas por el profesor Álvaro Ortiz Monsalve — continuador de la titánica labor_- en segundo semestre de la carrera de Derecho de esta facultad, la lectura del tomo primero de su obra me hizo conocer reservadamente a Valencia Zea, y la consultación, recordación y revisión de todos sus tomos me hicieron acostumbrarme a su discreta pero prodigiosa presencia, que me acompaña profesionalmente hasta el día de hoy, en el que por inmerecido honor debo referirme al autor y a la obra.

Muchos emocionantes momentos de mi vida como estudiante y profesional del derecho se han derivado de mi cercanía con la obra de Valencia Zea. Recuerdo vívidamente que me encantó su orientación germanista, que en un par de oportunidades llegué a revisar a mi casa, luego de que Ortiz, en su clase, hablara del tema con rigurosidad y precisión. El más significativo de todos esos momentos, por supuesto, está ligado a haber sido el relator de uno de los acostumbrados seminarios alemanes de un capítulo de Hans Hattenhauer, en su obra Conceptos fundamentales del derecho civil, en el que se hablaba de la persona y la personalidad (Hattenhauer, 1987, p. 13 y ss.), en la imperdible clase sabática de Ortiz Monsalve, que cerraba a las siete y cinco de la mańana. Mis incipientes balbuceos críticos contra Hattenhauer se derivaban de la precaria lectura de estudiante de segundo semestre que la tarde anterior había hecho del tomo I de Valencia Zea, tras el anunciado quiz. Nunca supe qué tanto fue del agrado de Ortiz y de Luis Alfonso Rojas — su monitor — mi deshilvanada y descabalada exposición crítica de Hattenhauer, pero gracias a ella obtuve una buena nota que me permitió subir al final un par de sufridos aprobados, logrados con mucho esfuerzo, a lo largo de todo el semestre.

Recuerdo, así mismo, que a pesar de haber visitado algunos cursos de alemán en el departamento de idiomas de esta querida Universidad llamó poderosamente mi atención una nota al pie del tomo III (De las obligaciones, sucesiv. Eds.: $\$ 37$, II.- Promesa bilateral de contrato), para cuando visitaba el respectivo curso con el profesor Carlos Rojas y que refería que en alemán existía una palabra para el precontrato, otra para el contrato y una más para el poscontrato: Vorvertrag, Vertrag Nachvertrag. Ese recuerdo fue tan decisivo y quedó tan acuñado en mi formación como jurista, que no en vano, incluso luego de haber sido auxiliar de magistrado y profesor de derecho, mi tesis doctoral terminó siendo sobre el precontrato (Castro, 2013).

El último de muchos acontecimientos, digno de mención, ocurrió en una fría noche de invierno del año 2005 en la biblioteca de la Universidad de Constanza en la República Federal de Alemania, que valga anotar se caracteriza por ser la mejor dotada de todo lo que fue el reino de Baden Württemberg, junto con las universidades de Heidelberg y Freiburg de Brisgovia. Siendo un recién llegado a adelantar mis estudios de maestría a esa 
De todos los temas que se podrían escoger y que guardan una profunda actualidad dentro de la obra ${ }^{2}$, he decidido tratar uno que pareciera no dar cuenta, en estricto sentido, de la labor de Valencia Zea, esto es, los fundamentos teóricos de su análisis, en especial de la posesión y la propiedad privada, sus efectos e importancia. Abordaré el tema desde una posición crítica, que pretende, a su vez, replantear las inadecuadas lecturas que se han hecho de la obra del profesor Valencia Zea y de las —en mi opinión - falsas apreciaciones que se han derivado de ellas, dentro del estudiantado.

universidad, becado por excelencia académica por el Estado alemán, por pura inquietud académica digité muchos nombres de los juristas nacionales más connotados en el buscador electrónico correspondiente: luego de un rato de desilusiones, la única obra de un profesor colombiano que aparecía referenciada en el catalogó local era La posesión de Arturo Valencia Zea. Acto seguido, con el número topográfico en un papel, más emocionado que curioso, caminé hasta la ubicación y admito que sentí una gran admiración al leer en la contrasolapa un sello que decía que ese libro había sido ordenado por la cátedra de un profesor alemán de la Facultad de Derecho, en el marco de sus investigaciones y que su adquisición había sido subvencionada con dineros públicos. Confieso que sostuve la obra en mis manos un momento: disfruté al máximo una extrańa sensación que yo calificaría como la de poder sentirme en casa: en la biblioteca de esta facultad. La verdad es que hasta ese día, solo en un par de ocasiones, había consultado otro ejemplar de esa obra. En una ocasión en la casa del mismo Valencia Zea, a cuya biblioteca accedí, por razón de haber guardado un cierto grado de amistad, que siempre atesoré, con el hoy profesor David Valencia Villamizar, nieto de Valencia Zea y quien fuera compañero de mi curso y con quien adelantamos una exposición sobre la estética en nuestra clase de Lógica Jurídica con el profesor Jairo Iván Peña Ayazo, durante el sexto semestre de nuestro pregrado. La otra ocasión en que sostuve esa obra en mis manos fue en la biblioteca de esta facultad.

Esa noche de invierno en la biblioteca de la Universidad de Constanza, luego de recordar esos dos eventos bibliófilos y de superar algún grado de emoción, releí en las profundidades de Baden, a pocos kilómetros de la Selva Negra, al lado del lago de Constanza, testigos silenciosos de tantos y tantos siglos de historia, La posesión de Valencia Zea, obra del que entonces fue para mí, una vez más y para siempre, uno de los grandes profesores de derecho civil del mundo entero: Arturo Valencia Zea, y al releerlo, repito, me sentí en esta facultad que me formó como abogado, de la mano de su obra, pero además con emoción y humildad, reconocí la grandeza de la obra de Valencia Zea. Durante los seis años que viví en Alemania adelantando mi Magister Llegum y mi Doctorado en Derecho, en varias oportunidades solicité el préstamo de la obra, para simplemente hojearla o releerla, en la lejana ciudad de Constanza.

2 Como la verdadera igualdad de derechos del hombre y de la mujer, de los hijos y el trabajo jurisprudencial que al respecto ha realizado la Corte Constitucional; la interpretación de la ley civil; el acoplamiento constitucional y civil por vía de la Ley 153 de 1887; el derecho comparado como prefacio a la verdadera filosofía del derecho que se evidencia en toda su obra; las clasificaciones de las obligaciones; el error común creador de derechos; la interpretación sistemática de la salida "suficiente" a la vía pública para la explotación del predio enclavado en materia de servidumbres, preceptuada por el artículo 905 del Código Civil y reinterpretada de hermosa manera por el tomo II de Valencia Zea; la noción de la buena fe exenta de culpa; las normas que modifican, derogan y articulan el Código Civil Colombiano; el espectro de influencia del derecho alemán en el mundo; la eliminación definitiva de los contratos reales del código; las funciones precontractuales; la familia, su concepción occidental y sus profundas modificaciones de los últimos tiempos; la necesidad de modificar nuestro código civil, eventualmente con su Proyecto de Código de Derecho Privado publicado por la Superintendencia de Notariado y Registro en dos oportunidades, etc.; la lista podría ser mucho más larga. 


\section{LeCTURAS DESDE LA TEORÍA IMPURA DEL DERECHO}

Cuando cursé una maestría en Filosofía del Derecho y Teoría Jurídica en esta facultad, visité un curso con el profesor Diego López, y allí escuché con algún grado de extrañeza sus afirmaciones sobre el salto formalista que había sufrido Valencia Zea en la segunda edición del tomo primero de su obra publicada en el año 1957, con respecto a la primera del año 1945. Posteriormente, leí con algún desencanto, pero además con un profundo desacuerdo, el texto traducido de la Teoría impura del derecho, de autoría del mismo profesor, en el que se encuentra una lectura teórica, en mi opinión, bastante desacertada e imprecisa, y por lo mismo desafortunada, de las dos primeras ediciones del primer capítulo del primer tomo del trabajo completo del profesor Valencia Zea.

Siempre creí que en semejante lectura del profesor Diego López no se hace justicia a la obra de Valencia Zea, pues de una forma bastante cándida se le tachaba primero de "jurista inquieto" convencido de las tesis de la Corte del 36, y luego, de haber tenido un giro positivista a la vera de una "mala lectura" de una mala traducción de Hans Kelsen realizada en la primera mitad de los ańos cincuenta del siglo xx. Por lo mismo, en la obra referida se le adjudica a Valencia Zea haber retornado pronto a una "comprensión mucho más positivista y dogmática del derecho" y, entre otras cosas, de utilizar a lo largo del libro palabras en castellano tales como proposición (que López deriva de una traducción de Rechtssatz ${ }^{3}$ ), puro y pureza ${ }^{4}$ (López, 2004, pp. 366 y 372).

\section{Crítica y PRopuesta}

Baste referir por ahora, que la obra de Valencia Zea, en términos dogmáticos, hace gala de una interesante articulación desde la primera edición hasta la última, tanto del ejercicio de la libre investigación científica del derecho predicada fundamental-

3 En realidad, la mejor traducción es precepto jurídico, o simplemente norma.

4 Por supuesto, esa lectura de Valencia Zea se antoja un tanto arbitraria, por decir lo menos; pero además bastante criticable por razones que se advertirán marginalmente en este artículo y que ahora no resulta preciso mencionar. Lo más grave es que promueve una concepción absolutamente falsa de la obra completa de Valencia Zea en términos de teoría jurídica. 
mente por Francois Geny (1925, p. 520 y ss.), como de las sentencias de la Corte Dorada del año 1936. De igual rigurosa manera, a partir de 1957 se incorporan a lo largo de las diferentes ediciones de la obra las teorías del neopositivismo kelseniano; que, para hacer justicia, son fuentes doctrinarias como cualquier otra, citadas por Valencia Zea en toda su obra. La citación doctrinal que de Kelsen y de Geny hace Valencia Zea son lo que se conoce como simples fuentes dogmáticas de la discusión hermenéutica (Larenz, 2010, p. 236 y ss. ${ }^{5}$ ), en tanto que la visión crítica de la posesión, pero por sobre todo de la propiedad, que componen el grueso del trabajo propositivo y final de la obra de Valencia Zea, son lo que a la postre constituiría la razón de fondo de la confección de la juiciosa y completa obra, que como trataré de evidenciar se soporta en otra clase de iusteoría. Las verdaderas fuentes de teoría jurídica que soportan la rigurosa obra de Valencia Zea lo llevaron a concebir la posesión como una forma de justicia material poscapitalista y a criticar profundamente la propiedad privada como una forma de alienación perversa, atentatoria de la verdadera libertad del ser humano. Como ya se podrá intuir, la obra de Valencia Zea, antes que gravitar sobre el formalismo o el antiformalismo, entre la inquietud de Kelsen, el pensamiento de la Corte de 1936 y el neopositivismo, gravita sobre fundamentos teóricos hegelianos y marxistas ${ }^{6}$, además plenamente correspondientes a una profundidad conceptual cosmopolita de la segunda mitad del siglo xx, bastante llamativa, como se verá adelante.

5 Tratando el tema de "La metodología como autorreflexión hermenéutica de la jurisprudencia". Sin embargo, como en otros escenarios lo he dicho, no comparto la traducción de la palabra Lehre por metodología, sería más adecuada la traducción de la palabra Lehre por dogmática (en subsidio doctrina), a la hora de ponerla en relación con la filosofía del derecho. La aposición de filosofía y metodología en la versión castellana conduce pues a confusiones.

6 Sobre la relación que jurídicamente puede predicarse entre Hegel y Marx, ver los ya tempranos y lúcidos razonamientos desarrollados por Stammler, en su Teoría critica del derecho (2011, p. 95 y ss.). 


\section{Las actuales lecturas hegemónicas ${ }^{7}$ sobre la obra de Valencia Zea, como formalis- ta, han contribuido a una visión bastante criticable, pero sobre todo falsa ${ }^{8}$, y han}

7 Las "malas lecturas" que tanto menciona y perfila el profesor López tienen pues en su teoría impura un paradigma peligroso, cuando se hace referencia a Valencia Zea desde propuestas iusteóricas tan simplistas y, en mi opinión, no ajustadas a los escritos y alejadas de la realidad. Es precisamente esta promoción de relecturas lo que ha generado visiones no muy certeras del profesor Valencia Zea en Latinoamérica, y principalmente en los seguidores de López.

Cabe anotar, sin embargo que a pesar de las críticas que se pueden hacer a los sistemas categoriales de la Teoría impura del derecho, a pesar de su imperfección y de ser casi tan pretensiosos, como lo fueron los propuestos en la 20th century Legal Philosophy Series, de la Harvard University Press y/o en la obra de Josef L. Kunz, deben ser reconocidos como un primer y real intento de dar cuenta, en la era contemporánea, de las lecturas jurídicas latinoamericanas. En efecto, vale resaltar que la teoría impura del profesor López trata de tener una visión abarcadora, desde los primeros tratadistas del derecho civil, como Champeau y Fernando Vélez, por ejemplo, hasta los ańos cincuenta del siglo xx, y eso justifica su intento; pero en parte, cobra como precio "malograr", entre otros, diría yo, a Valencia Zea, en un marco histórico iusteórico. Si quería López analizar los saltos del antiformalismo al positivismo hubiese podido ubicar (y estudiar) a otros tratadistas de derecho civil como Álvaro Pérez Vives, a Nicasio Anzola o a Eduardo Zuleta Ángel (en verdad muy interesante al respecto) (Zuleta, 1974, p. 15 y ss.) o a muchos otros juristas, mas no a Valencia Zea.

Al respecto, pareciera que la diferencia es que cuando Kunz escribía su obra, la producción latinoamericana era mucho más mensurable y adjudicable en términos de teorías o discursos filosóficos. Esas, tal vez (lo abarcador de la obra de López Medina y la prolífica producción de los últimos sesenta años en Latinoamérica), sin embargo, sean las principales razones de que la lectura que se hace sobre la obra de Valencia Zea sea tan corta y en parte tan arbitraria. En efecto, tratar de leer toda la producción jurídica latinoamericana desde el formalismo y el antiformalismo o desde la equívoca o mala lectura (missreadings) hecha en la periferia de nuestros países, de textos importados de los centros de producción jurídica, es una posición demasiado simplista.

8 López en su obra propone una filosofía jurídica propia; y, dentro de ella, una recreación de un espacio diferencial entre sitios de creación y sitios de recepción jurídica. En ese marco, propone a su vez, un eje de formalismo y antiformalismo desde el cual puede aglutinarse una comprensión del espacio jurídico latinoamericano. Sin embargo, afirma López, "si se le compara con otros sitios periféricos de recepción, América Latina parece ser uno de los sitios iusfilosóficos menos interesantes ya que es considerado como un mero apéndice del pensamiento jurídico europeo". A pesar de que se pueda admitir que Latinoamérica pueda ser una extensión de un proyecto civilizatorio inacabado, como lo sostiene López, en ese contexto, la relectura entre formalismo y antiformalismo no resulta adecuada como eje de ninguna clase de teoría jurídica seria. Una precisión conceptual final sobre este punto es que para muchos autores de talla mundial Latinoamérica es un centro de producción jurídica de primera. Solo por mencionar dos, ya dedicados a la unificación del derecho europeo, como Reinhard Zimmermann (ver su extensísimo e interesante trabajo en el Max Planck Institute, para el derecho privado); o, ya expertos en derecho comparado e historia del derecho civil, como Eugen Bucher, entre otros muchos, en su pertinente texto: Zu Europa gehort auch Lateinamerika!

Diverso asunto es que en Colombia la dogmática jurídica iusprivatista haya sido utilizada por algunos como una forma de perpetuar el statu quo dominante desde los ańos cincuenta del siglo XIX, pero ello no es óbice, ni razón necesaria y suficiente, para crear teorías descabaladas y alejadas de toda realidad, además fácilmente falseables desde muy diversas ópticas: dogmáticas, iusteóricas, iusfilosóficas o críticas. Así mismo, puede que sea certera la apreciación de Gómez Hernández, Bersarión, según la cual se enseña derecho civil en textos antiguos y/o en nuevos nacionales (basados) en textos antiguos; pero eso tampoco es razón suficiente para catalogar de manera equívoca la obra de Valencia Zea. Esta para nada es un ejemplo tan siquiera medianamente adecuado de 
la especie de retractación de la investigación científica del derecho (antiformalismo, que ubica a Valencia como un jurista inquieto), como lo propone López, al neopositivismo. También resulta inadecuado tenerlo por el definitivo epígono receptor de la teoría pura del derecho de Hans Kelsen (formalismo), respecto de quien Valencia Zea, a su vez, habría recreado una supuesta nueva lectura y uso local, según López.

En general podemos decir que López en su teoría impura sobredimensiona gravemente la inclusión de la citación esporádica de la teoría pura del derecho de Hans Kelsen, en la nueva edición del tomo I de Valencia Zea en 1957. Haciendo barrido de nichos citacionales, es claro que Kelsen no resulta siendo citado más de ocho veces en esa edición de 1957 y en por lo menos un par de esas citas Valencia disiente de Kelsen.

En efecto, López (2004, p. 367) propone seis cambios que reflejan el tránsito de la teoría que soporta la obra de Valencia Zea, entre 1945 (pasando de ser un defensor de Geny y un jurista inquieto) y 1957 (a ser un formalista normativo kelseniano), que él mismo resume así:

1.- Ya no se postula más que el derecho es una ciencia social, sino que es puramente normativo, una ciencia del deber ser, en el que se dan vínculos entre hechos y consecuencias. Sin embargo, el argumento de López resulta incompleto: si bien es cierto que Valencia cita predominantemente a Kelsen, en sus primeras 19 páginas en 1957, lo cierto es que sigue citando, entre otros, p. ej., a Ihering en cuanto a los fines del derecho, y por supuesto a Stammler para hablar "de la cooperación para la satisfacción de toda suerte de necesidades" (Valencia, 1957, p. 25 y ss.). Así mismo, a lo largo de la obra hay muchos argumentos sociológicos, algunos de los cuales se postularán a continuación.

2.- Debe haber una estricta separación entre derecho y moral. Pero Valencia afirma ya en la página 21 de la edición de 1957 que existen unos conceptos fundamentales que corresponden a unos supuestos (o imperativos, de alguna manera, categóricos), que deben ser regulados, personalidad, Estado, propiedad y familia. Y en este punto, incluso si se quisieran obviar los parámetros de personalidad y estado como ideológicos; los dos temas restantes, esto es, propiedad y familia devienen per se, de una ideología que a su turno implica alguna forma de moral, o en subsidio de ética. Pero además la teoría pura del derecho, que digiere y postula Valencia, es eminentemente axiológica, como bien se denota en las páginas 51 y 68, en donde citando a Alzate Noreña, a Arteaga, a J.J. Gómez y a Nieto Arteta, se evidencian claras conexidades con la naciente Facultad de Filosofía de la Universidad Nacional de Colombia. Valencia expone las ideas esenciales del Código Civil (1957, p. 51 y ss.) y denota su conocimiento de la lenta maduración académica del análisis sobre el ambiente axiológico de la teoría pura del derecho, que al respecto exponía ya hacía diez años Carrillo (1947, p. 47-83). La cercanía de la Facultad de Derecho con el naciente instituto de filosofía en la Universidad Nacional de Colombia así permite ratificarlo. Cabe anotar que López no aborda extrańamente ese estado del arte sobre la asunción de Kelsen en Colombia (Carrillo, 1947, pp. 47-83).

En similar sentido puede consultarse a Mejia Quintana, cuando, haciendo un recuento histórico, afirma que: "En Colombia como en general en la región andina y América Latina el derecho terminó operando como una ideología más, cambiando su función organizadora, por una 'función simbólica', apologética y dominadora, enfrentándose, en tanto metadiscurso" (Mejia, 1997, p. 79).

3.- El derecho no debe perseguir fines o propósitos politicos. Así mismo, como se ha dicho, nuevamente en la página 26 de la misma obra, Valencia expone que existen tres fines generales y supremos de todo derecho, cuyo valor jerárquico se ordena así: convivencia pacífica de los hombres libres, conservación y supervivencia de un pueblo o nación en la Historia. Lo que, además de sonar muy hegeliano, entre otras cosas, evidencia el reconocimiento de fines en el derecho realizado por Valencia Zea, no tanto desde la teleología jurídica pura (que implicaría una lectura de alguna manera kelseniana), sino de objetivos predicables de todo ordenamiento a las voces de Ihrering, Recasens Siches, Radbruch o Stammler (en su economía y derecho desde el materialismo histórico); y, esa posición (de reconocer fines en el derecho), además, era entonces una opción considerada como bastante válida por el mismo Valencia Zea (Valencia, 1957, pp. 24 a 26). 
4.- Las reglas de interpretación legal contenidas en los artículos 25 a 32 del Código Civil positivizan, en el ámbito local, el método tradicional de interpretación originalmente expuesto por Savigny. Acá nuevamente existe una lectura errada de López, pues además de que los artículos 25 a 32 son enunciados en las dos ediciones escogidas por él, del primer tomo, lo cierto es que así mismo Geny y su método de interpretación siguen siendo citados prolijamente a lo largo de la edición de 1957 (incluso más veces que Kelsen), en la parte pertinente sobre interpretación de la ley y sobre todo en la parte crítica de la interpretación tradicional (Valencia, 1957, pp. 105110). Huelga anotar, eso sí, que en la parte crítica de la interpretación exegética Geny pierde el papel protagónico que tuvo en 1945 y que, para 1957, es asumido por Radbruch, Enneccerus, Lehmann y su allgemeiner Teil des $B G B$ o parte general del вGB; y, por sobre todo, la así llamada, Entwicklungsjurisprudenz in der evolutionische Richtung de Enneccerus o "jurisprudencia desarrollista en la dirección evolutiva” (Valencia, 1957, p. 136). Pero, por sobre todo lo anterior, Valencia va a desarrollar, en todas las ediciones de su obra, las diversas interpretaciones hechas por la "Corte Nueva" sobre determinados temas específicos que él empieza a ver, desde entonces, como dominantes, siguiendo entre otros a Tafur Morales, con su obra La nueva jurisprudencia de la Corte (Valencia, 1957, p. 131); citando al magistrado ponente respectivo, p. ej., Zuleta Ángel (Ibíd.: p. 129); Hinestrosa Daza (Ibíd.: p. 130) o la prevalencia de la interpretación histórica que refería Antonio Rocha en el prólogo de la obra de obligaciones de Álvaro Pérez Vives (Ibíd.: 127-128). Así mismo, se siguen citando las construcciones de la "Nueva Corte", de 1935 a 1940, bajo el título, Principales construcciones jurisprudenciales que complementan la legislación civil, y de hecho se enumera a sus miembros así: Antonio Rocha, Eduardo Zuleta Ángel, Ricardo Hinestrosa Daza, Arturo Tapias Piloneta, Miguel Moreno Jaramillo, J. Francisco Mujica y Liborio Escallón (Valencia, 1957, p. 63 y ss.) y se menciona que el Código Civil se encuentra "profundamente complementado y corregido en virtud de importantes construcciones jurisprudenciales". A su turno, se mencionan como en la primera edición de 1945 las principales doctrinas: abuso del derecho, enriquecimiento sin causa, imprevisión en los contratos, teoría de la apariencia de derechos y la buena fe exenta de culpa, doctrina sobre fraude a la ley, construcciones sobre la posesión, error de derecho, error sobre los móviles y teoría de la causa, nueva doctrina sobre la simulación, responsabilidad civil, Ley 28 de 1932. Al final, Valencia cita once grupos de sentencias. De donde se sigue que Valencia, primero no fue un jurista inquieto del 36 al 45, y menos aún, nunca dejó de reconocer, es más, yo diría que fue el principal defensor, en todas las ediciones de su tomo I, pero en general en toda su obra, de la Corte de 1936, catalogada como dorada (Valencia, 1957, pp. 64 y 65). El supuesto "giro puramente kelseniano" aducido vehementemente por López resulta ser una apreciación bastante imprecisa.

5.- El origen de las normas jurídicas en una teoría pura del derecho, se analiza sin conexión alguna a realidades de naturaleza sociológica; pero como se ha dicho, Valencia dedica buena parte de la edición de 1957 a analizar la actualización del código a la realidad social, p. ej., la adecuación a la vida industrial de los pueblos, a través de la teleología por parte de la "Nueva Corte" (v. p. ej., Valencia, 1957, pp. 130 y 131, sobre el artículo 2356).

6.- Para entender una norma jurídica se debe examinar su estructura lógica Rechtssatz. Sin embargo, esa conclusión ligera parece diluirse cuando al leer un poco más de la edición de 1957 del tomo, Valencia acoge con entusiasmo la adecuación histórica y sociológica que del artículo 2356 hizo la Corte Suprema de Justicia en el año de 1938 (1957, pp. 129-131).

Por último, vale anotar que además al leer con cuidado a López se reconoce que Valencia desde 1945 citaba a Kelsen a través de Recasens Siches, en la nota al pie número 39 del tema específico, de donde se sigue que el mal argumentado "salto formalista" en realidad no es tan certero (López, 2004, p. 362).

Por otro lado, de manera atípica, ya en 1957 Valencia menciona la importancia de la doctrina civilista rusa y acota: "sobre los principios generales que informan el derecho socialista de Rusia, son guías valiosos las obras de Marx y Engels, Vishikski, Lenin, Denisov, Touretski y Kareva” citadas por R. David (Valencia, 1957, p. 163). 


\section{generado mayores complicaciones iusteóricas’; ya que al tratar de dar cuenta de la}

9 La citación de Stammler que se hace desde la primera edición del primer tomo de Valencia Zea pareciera indicar que la lectura del derecho desde el materialismo histórico fue una constante en la obra de Valencia Zea. Esta opción se ofrece como la más adecuada y es la que acojo en el presente intento (hay otras constantes históricas críticas, como la citación desde la edición de 1957 y hasta la última edición de Valencia solo, de autores como Ots Capdequi, en su obra: Manual de historia del derecho español en las Indias (Cfr. Valencia, 1957, p. 40 y ss.), presente en todas las ediciones hasta 1992). Y se ve además fortalecida, porque Valencia Zea desde la edición del tomo II (Derechos reales) de su obra en 1958 no hace una crítica de la propiedad desde visiones socialistas (socialistas utópicos, Saint Simon o Marx, que solo aparecerán en posteriores ediciones), pero sí habla claramente en la parte III del Capítulo I del título Tercero, dedicado a la propiedad (Valencia, 1958, pp. 155-167), de los caracteres sociales de la propiedad privada, para referir mandatos constitucionales no solo de la Constitución de 1886, sino de la Constitución de Weimar de 1919, la Constitución mexicana de 1917 (modificada en 1948), la Constitución de Cuba de 1940, la Constitución de Bolivia de 1945 y la Constitución de Brasil de 1946, entre varias otras. Así mismo, en una interpretación muy interesante, menciona que el artículo 669 del Código Civil ya había postulado el efecto negativo de la función social de la propiedad al mencionar que el derecho de dominio no podría ser "contra ley o contra derecho ajeno" (Valencia, 1958, p. 160). Tras lo anterior, se admitirá que una visión de la propiedad en semejantes términos (de constitucionalismo comparado) era algo en realidad bastante atípico para el año de 1958 que corría, para cuando se edita esta edición del tomo segundo del profesor Valencia Zea.

Sin embargo, admitiendo la pluralidad de criterios dogmáticos y teóricos que deben enriquecer la ciencia, se debería aceptar también que el corifeo general reconstruiría - hoy en día - el trabajo del profesor Valencia Zea, desde diversas orillas que no consideramos adecuadas. En efecto, entre otras visiones, podrían hacerse otras varias lecturas subsidiarias propias de la teoría jurídica, pero su sustento bibliográfico se ofrece más débil. Una, entre muchas de ellas, avizorada por algunos (véase, p. ej., entre otros escritos, a Villar Borda, en Arturo Valencia Zea, El hombre, el jurista, quien se refiere solo a los seis tomos de la obra de derecho civil, pero no hace acotación alguna a La posesión o a Origen, desarrollo y crítica de la propiedad privada: (Valencia Zea, el Hombre, el Jurista, 1995, pp. 79-80)), nos indicaría que así, como se habla de un primer Ihering y un segundo Ihering o de un primer Kelsen y un segundo Kelsen, incluso de manera más amplia, en la filosofía analítica, de un primer Wittgenstein y de un segundo Wittgenstein, de manera analógica, podría hablarse de un Primer Valencia Zea (dogmático) y de un Segundo Valencia Zea (socialista). Sin embargo, como he dicho, no se advierte una ruptura argumental definitiva a lo largo de todas las ediciones del trabajo completo de Valencia Zea. El maridaje de Valencia Zea con la interpretación socialista del derecho es una constante que, como se ha dejado indicado, se perfila progresiva, desde la citación de Stammler en su primera edición de 1945 en su primer tomo, pasando por la visión constitucionalista comparada de la función social de la propiedad en la edición de 1958 de su tomo segundo, hasta las progresivas críticas de la propiedad que Valencia incorpora más y más en las sucesivas ediciones del mismo y que serían en su esencia reivindicativas y el acicate para la confección de sus libros La posesión y Origen, desarrollo y crítica de la propiedad privada.

Lo que sí parece evidenciarse a través del aumento y profundización respecto de esos temas y críticas es que Valencia se toma confianza, poco a poco, en la incorporación de estas. Al respecto, parece necesario ser bastante preciso: no existe en realidad un giro, sino que desde el principio existe una clara y evidente influencia del pensamiento socialista en la obra de Valencia, pero es tímidamente expuesta al inicio. Básicamente, porque de acuerdo al ejercicio de derecho comparado, realizado permanentemente por Valencia (consistente en la consultación de las obras de derecho civil europeas agotadoras y divididas por tomos - temas, y cuya confección era el objetivo de Valencia Zea en el marco nacional), no resulta tan siquiera permitido incorporar, en un tratado de esa índole, críticas ideológicas ajenas a la pura dogmática, tanto constitucional como civilista. Solo va a ser hasta luego de Mayo de 1968 que esa posibilidad aparece como certera, de manera lenta en el corifeo del derecho civil comparado europeo y americano. Nótese como solo hasta la cuarta edición del tomo segundo, en el año 
obra, falseando su verdadera contribución y auténtica propuesta, guían equívocamente la investigación. La crítica aquí presentada se dirige tanto a estos desarrollos ulteriores ${ }^{10}$ y derivados de la teoría impura, como a la obra misma de López; sin embargo, ha de dejarse sentado conjuntamente que fue esa ligerísima lectura lo que provocó irreflexivamente esas consecuencias, más lúdicas e imaginativas literariamente, que serias en términos de iusteoría.

\section{LA TEORÍA JURÍDICA EN PERSPECTIVA}

Hasta este punto, sin embargo, cabe anotar que la teoría jurídica tiene otras concepciones mucho más ricas, más descriptivas y minuciosas que la propuesta por López. $\mathrm{Y}$ ya que sus sistemas categoriales son bastante estrechos y poco descriptivos es necesario focalizar aquí, mínimamente, qué se ha de entender o cómo se pretende abordar la teoría jurídica, de manera previa, a hacer cualquier clase de acercamiento a la obra de Valencia Zea.

\subsection{Precisiones conceptuales}

Esta brevísima exposición no busca ser agotadora, sino que obedece a una enumeración sencilla sobre los elementos más importantes de la teoría jurídica en general y que se evidencian como necesarios y suficientes para escrutar la obra de Valencia Zea. En efecto, parece complejo abordar el estudio de los fundamentos teóricos de la obra de un autor (en especial, uno como Valencia Zea: extenso, profundo, diverso y multidisciplinario), sin tener una cierta claridad sobre lo que ha de entenderse en el

de 1973, se cambia el capítulo segundo del título tercero dedicado a la propiedad de "Extensión y contenido de la propiedad especialmente de la inmueble" por uno que se denominará "Las grandes doctrinas críticas de la propiedad privada, especialmente la capitalista”. Por las anteriores razones resultaría impropio hablar de un Segundo Valencia Zea contradictorio o que se retracta de sus posiciones respecto de un primero; pues desde la edición de su tomo segundo, en 1957 hasta la última que publicó en vida, se migra de tímidas exposiciones sobre la función social de la propiedad en términos constitucionales comparados, a la exposición crítica ideológica in extenso que de la propiedad, en especial la capitalista, se hizo a partir de la tercera parte del siglo xx y que se consolida vigorosa, luego de mayo de 1968.

10 Como, por ejemplo, las lecturas de Gómez Hernández, Bersarion, y Agudelo, Carlos Alberto, entre otras, derivadas de la interpretación propuesta en la teoría impura por López. 
respectivo ejercicio por teoría jurídica ${ }^{11}$. Pero, adicionalmente, el asunto de adjudicar, entre otros muchos filósofos, a Hegel y muy especialmente a Marx, las influencias teóricas o sociológicas de la creación jurídica de algún autor, ha sido también bastante problemático a lo largo del siglo $\mathrm{xx}^{12}$.

\subsubsection{La aproximación de Bernd Rüthers}

El profesor Rüthers, uno de los grandes exponentes de la teoría jurídica alemana, menciona que

la teoría jurídica trata de determinar afirmaciones generales y verificables sobre las normas jurídicas y su forma de afectación sobre la sociedad y la economía. Ello también lo hace la filosofía del derecho y la doctrina general del derecho, (pero) la teoría jurídica es el intento de reconocer y de describir al derecho y

11 La tendencia sociológica y funcionalista de Valencia Zea no permite abordar su obra desde "la delimitación pulcra del objeto de conocimiento del derecho" de que hablaba Kelsen (2009, p. 24), sino que, como se verá, es necesario abordar la discusión desde lo más reciente y adecuado de la producción sobre el entendimiento de la teoría, en la segunda mitad del siglo xx, para hacer la más adecuada lectura de la ya definitiva obra de Valencia Zea. Véase Alexy (2007, p. 93 y ss.; 2008, p. 89 y ss.).

12 Se podría tener por cierto que fue Rudolf Stammler quien por primera vez se refirió, con algún detenimiento al tema, en su obra Economía y derecho, según la concepción materialista de la historia: una investigación filosóficosocial y quien pertinentemente para nuestro estudio menciona que "cuando una norma jurídica sea teóricamente justa podrá demostrarse examinando y decidiendo en el plano crítico qué normas jurídicas son las que bajo circunstancias empíricamente dadas corresponderían a las miras últimas de toda vida social, por donde podrá verse si es que donde el Derecho histórico tradicional se ajusta exactamente, en la situación concreta de que se trate, a la misión que conforme a la ley última que lo rige debe proponerse todo orden jurídico, o si, por el contrario media una dualidad entre lo que rige como Derecho positivo y lo que, a tenor de lo indicado, debiera ser Derecho" (p. 286).

Así mismo, desarrolla una relación entre economía y derecho y posteriormente entre el derecho y los a él sometidos (p. 358 y ss.). En el siglo xx, entre otros N. Reich (con su marxistische Rechtstheorie) y más conocidos en nuestro medio, por supuesto el profesor Norberto Bobbio, a quien analizaremos puntualmente más adelante y más recientemente Duncan Kennedy, en su obra Izquierda y derecho, ensayos de teoría jurídica crítica, quien ha trabajado una alternativa fenomenológica de izquierda, basado en los manuscritos económicos y filosóficos de Marx (Cfr. p. 85 y ss., 90 y ss.). Contribuyen desde otros espectros a enriquecer esa discusión, entre muchos otros: Giorgi (1976, pp. 271-277) y Frankenberg (2011, pp. 67-84).

Sobre un estado del arte más o menos actualizado de las críticas a Paschukanis (tal vez el representante más conocido de la teoría jurídica marxista, en nuestro medio), véase: Warenform und Rechtsform: Paschukanis' Rechtstheorie de Andreas Harms, disponible en http://www.rote-ruhr-uni.com/cms/IMG/pdf/Harms_-Warenform_und_Rechtsform.pdf (fecha de última descarga: 15 de junio de 2014). 
al respectivo sistema jurídico, como tales, en el real discurrir de sus funciones.

(Traducción mía) (Rüthers et al., 2013, p. 13)

Esa definición, bastante consecuente con la teoría jurídica alemana, resulta sin embargo de alguna manera desconocida en nuestro medio. A pesar de ello, es muy adecuada en términos de la delimitación correspondiente.

\subsubsection{La visión panorámica de Karl Larenz}

En la primera parte de su obra Metodología de la ciencia del derecho, Karl Larenz hace un válido recuento de lo que fue y es lo más representativo de la teoría del derecho y la metodología jurídica en Alemania, desde Savigny con la escuela histórica del derecho y jurisprudencia de conceptos y hasta Kriele con su argumentación jurídico racional (Larenz, 2010, pp. 31-174). Una primera aproximación a esta obra da cuenta de la utilización inadecuada de conceptos por parte de muchas teorías. Así, la sinonimia entre sistema y filosofía o filosofía y teoría jurídica; o entre teoría jurídica, retórica y formas de argumentación, evidencia que la teoría del derecho en estricto sentido es algo más complejo de delimitar propedéuticamente de lo que en principio pareciera. Sin embargo, haciendo una unificación de las diversas teorías expuestas, pareciera ser que Larenz entiende la teoría jurídica como "los métodos de interpretación y aplicación jurídica" que se han utilizado a lo largo de la historia alemana, partiendo evidentemente de supuestos filosóficos e históricos. La complejidad de cada uno de los métodos implica para Larenz la necesaria exposición de cada uno de ellos y su justificación histórica, de manera tan minuciosa como sea posible. Sin embargo, por razón de la misma circunstancia, se percata el autor de una cierta imposibilidad de adjudicarle una única tarea o función a la teoría jurídica, y por lo mismo se abstiene, dentro de su acostumbrada rigurosidad, de ofrecer una noción o concepto actual que la contenga de manera liminar.

\subsubsection{Marx y la teoría jurídica de Norberto Bobbio}

De otro lado, es ya clásico el texto del jurista italiano Norberto Bobbio — que para el ejercicio de hoy resultará muy útil— sobre "Marx y la teoría del derecho". En él resulta significativa y valiosa su eliminación de la concepción de la teoría jurídica. 
Bobbio prescinde de definir per se las teorías y opta por "referirse a ejemplos concretos de obras que (entre juristas), estamos todos de acuerdo, en considerar como obras de teoría del derecho". Enumera trabajos como "los de Kelsen, de Ross, de Hart o por último de Luhmann". Para Bobbio

los grandes temas de la teoría del derecho [... son los temas ligados al origen, la naturaleza, la estructura, la función de sistemas normativos y a la distinción entre el sistema normativo que llamamos habitualmente derecho y todos los demás sistemas normativos (o también no normativos); como también el origen, la naturaleza, la estructura y la función de los elementos simples de estos sistemas que son las normas (2001, pp. 188-189).

Así mismo, de las juiciosas confrontaciones que Bobbio hace entre la escasa producción iusteórica marxista y los tipos de textos enumerados o que se dedican a las tareas también por él mencionadas, surge la necesidad, siguiendo a Treves, de considerar

(la obra de Marx), bajo un perfil no tanto de la teoría general del derecho, sino de la sociología del derecho, más particularmente de la teoría sociológica del derecho en la que Marx habría hecho algunas contribuciones que no pueden descuidarse. Estas contribuciones consisten, según Treves, en haber puesto el derecho en relación con el conflicto social, en haber relacionado el derecho con la sociedad dividida en clases y por lo tanto haber previsto la extinción en una sociedad sin clases, y en haber reinterpretado la doctrina del derecho natural como teoría de la legitimación del derecho positivo.

En otra oportunidad, referida igualmente en el mismo texto, Bobbio al diferenciar entre las teorías formales del derecho de las teorías sociológicas, hizo corresponder esta distinción con la que hay entre teorías estructurales y teorías funcionales del derecho. Así, luego de reflexionar sobre ello, Bobbio considera que

en Marx existe in nuce una teoría sociológica del derecho, es decir una teoría que considera el derecho en función de la sociedad y de las relaciones sociales inferiores y que no por casualidad redefine el derecho, no por medio de la es- 
tructura del ordenamiento jurídico, como han hecho las teorías formales, sino mediante su función. (Bobbio, 2001, pp. 195-197) $)^{13}$

\section{ConteXto histórico y aCadémico de Arturo Valencia Zea}

Pareciera, entonces, siguiendo a Bobbio, que antes de hablar de una teoría jurídica marxista, de lo que puede hablarse, con cierta rigurosidad, es de una influencia de teorías sociológicas del derecho, derivadas de las referencias aisladas de Marx a lo jurídico. Sin embargo, a estas alturas, siguiendo los cánones del materialismo histórico, y tenida en cuenta por lo demás la propuesta total de la obra de Valencia Zea, se torna oportuno contextualizar la época y las corrientes académicas que rodearon su producción, en especial la parte propositiva final de su trabajo.

Lo primero que es necesario perfilar a la hora de iusteorizar sociológicamente a un autor, como Hobsbawm o el mismo Bobbio lo sugieren, es tener una perspectiva completa de su obra: haberla leído en su totalidad ${ }^{14}$. A renglón seguido, pareciera imprescindible desglosar, de todo el andamiaje dogmático, lo que podría denominarse las partes más propositivas del autor ${ }^{15}$.

13 Así mismo, nos recuerda Bobbio, en el libro los Grundrisse o Fundamentos de Marx afirma que "entra en juego el momento jurídico de la persona”, a propósito del intercambio entre sujetos formalmente libres e iguales, o sea a propósito de la institución típica del derecho privado que es el contrato”. De otro lado y por último, nos recuerda Bobbio, en El capital "se encaran una y otra vez problemas jurídicos, desde la propiedad hasta la legislación social”.

$\mathrm{Al}$ respecto, disiento en parte de la observación de Bobbio, según la cual la producción crítica de Marx en torno a lo jurídico es escasa, ya que existen textos muy interesantes de Marx atacando la concepción de la propiedad de Savigny, que fue su profesor en Berlín; y, por supuesto, la filosofía del derecho de Hegel (Attali, 2007, p. 57) y disponible y libre en internet: Zur Kritik der Hegel'schen Rechtsphilosophie, o De la critica de la filosofia del derecho del querido Hegel.

14 Suena a una verdad de Perogrullo, pero tengo serias dudas sobre la completitud del conocimiento del profesor López y de sus discípulos sobre la obra de Valencia Zea.

15 Aquí, por supuesto, vale explicitar lo que resulta evidente: desde el momento en que cualquier conjunto de ideas sobrevive a su creador, cesa de estar confinado a sus intenciones y contenido originales. Dentro de los amplios límites alcanzados por la humanidad para interpretar, o incluso de la disposición humana para confirmar una noción o una premonición con la asociación de un predecesor deseable (ojalá expositor reposado y valorado, como es sabido), las relecturas de los idearios constituyen el grueso de la actividad intelectual humana. El conjunto de ideas está sujeto a un amplio e impredecible abanico de modificaciones y transformaciones prácticas y teóricas, como bien lo comprenden Hobsbawm desde el historicismo crítico o Larenz desde las metodologías de la teoría jurídica. Así, es claro que el Adam Smith de 1776 nada tiene que ver con el Adam Smith de hoy en día. Sin embargo, lo cierto es que esas libertades interpretativas tienen — deben tener- algunos ciertos límites 


\subsection{LAS RELECTURAS MARXISTAS DE 1945 A 1990}

La obra de Valencia Zea se desarrolló fundamentalmente a lo largo de 45 años: entre 1945 y 1990, uno de los periodos más ricos y complejos en términos políticos, económicos y sociales de la humanidad y que por fuerza, entonces, ha de contex-

de seriedad, rigurosidad y sensatez. Hacer teoría jurídica sobre la obra de Valencia Zea, teniendo en cuenta exclusivamente las dos iniciales ediciones del primer capítulo del tomo primero de la obra total, sería tanto como juzgar la obra de García Márquez por el primer discurso que dio en su vida y por uno de sus cuentos menores: alguno de los doce peregrinos, por ejemplo. Una tarea hermenéutica de semejantes características solo cobra relevancia - y por supuesto legitimidad y validez — cuando, entre otros casos, gran parte de la obra de un autor se ha perdido para siempre, como ocurre con Sócrates o Sófocles, pero no es el caso de Valencia Zea, cuya obra se mantiene íntegra para la posteridad. Estas anotaciones, en alguna medida impertinentes, cobran peso, por cuanto los desprevenidos lectores de López no tenemos aún claro cuáles fueron los criterios que se utilizaron para delimitar de semejante manera el objeto de estudio de la obra de Valencia Zea. En efecto, las ediciones de 1945 y de 1957 (primera y segunda) no son representativas por su diferencia: es demasiado artificiosa la implementación argumental, según la cual previamente a 1957 se hallaba recién traducida y publicada la reine Rechtslehre o La teoría pura del derecho de Hans Kelsen, y que Valencia Zea la habría entonces citado en la nueva edición de ese mismo ańo, porque habría sufrido un giro positivista. Hacer semejantes apreciaciones implica un falseamiento científico grave, fundamentalmente por dos razones: la primera es que Valencia Zea leía alemán y cita pertinentemente a un número significativo de autores alemanes no traducidos a lo largo de toda su obra. La citación hecha por Valencia de Kelsen en español obedecería más a una actualización de discursos accesibles a los públicos de Bogotá y no a un reciente abordamiento y comunión de Valencia con esas teorías. De otro lado, las citas que de Kelsen se producen en el tomo I de la obra, para 1957, parecieran ser más críticas, que de acogimiento cerrado de las mismas; por ejemplo, cuando se cita por primera vez a Kelsen en la obra, se afirma: "8.-Diferente de la teoría de la norma que acabamos de exponer, es la doctrina presentada por Kelsen y sus discípulos (escuela de la "Teoría pura del derecho")

$[\ldots]$

Existe, pues, una diferencia fundamental entre la teoría de la norma desenvuelta aquí y la presentada por la "Teoría pura del derecho.

1) para nosotros el primer tronco de la norma está constituido tanto por la conducta ilícita como por la conducta lícita. El contratar, el casarse, etc. Son hechos jurídicos lícitos; para Kelsen, no lo son.

2) La consecuencia jurídica o segundo tronco de la norma son los efectos inmediatos de todos los hechos o acciones que forman el primer tronco de la norma, es decir, los derechos subjetivos, las penas y ciertos estados. Para Kelsen, es el acto coactivo que se sigue a la conducta ilícita” (Valencia, 1957, pp. 16-17). Ello no obsta para que en puntuales anotaciones Valencia Zea reconozca la ventaja de contar con una teoría pura del derecho, más como estado del arte de la discusión, que como mérito claro de Kelsen (Valencia, 1957, p. 18), e igualmente, parece bastante dudoso que la lectura del 57 de Kelsen en Bogotá (puramente axiológica) tuviera la significación que pretende ser adjudicada por López (Carrillo, 1947, pp. 7-8 y 47 y ss.). Por último, la producción de Valencia Zea era derecho civil, más no derecho público, que pareciera ser el foco central de las disquisiciones de Kelsen. Valencia Zea tenía claro que la aplicación de la teoría instrumental y formalista de Kelsen al derecho privado era bastante limitada y de hecho la siguiente cita de Kelsen a las recién referidas tiene que ver con la diferenciación clara que es menester hacer entre derecho público y derecho privado (Valencia, 1957, p. 31). 
tualizarse mínimamente en términos académicos ${ }^{16}$, para luego sí poder hacer teoría jurídica de estirpe sociológica ${ }^{17}$. El entendimiento de este título será desarrollado en tres partes fundamentales.

1. De 1945 a 1990, para cuando Valencia Zea desarrolla toda su obra, pareciera que tuvo lugar la materialización más prolija de obras de todos aquellos intelectuales que, declarándose marxistas, buscaban dar cuenta de la afirmación contenida en la décimo primera tesis sobre Feuerbach: "Hasta ahora los filósofos sólo han interpretado el mundo: la cuestión es cambiarlo". Valencia Zea podría ser catalogado como uno de esos intelectuales marxistas, pero vale al respecto precisar algunos aspectos.

\section{Lo primero es que en la obra de Valencia Zea no se produjo una comunión política} con las aberradas prácticas socialistas o comunistas del marxismo en Rusia o China o en cualquier otro país que adoptara un régimen guiado por la filosofía marxista; por el contrario, la apropiación que de Marx hace Valencia Zea va a tener un contexto puramente intelectual bastante bien fundamentado, como ahora se verá. Como bien lo postuló el marxismo de preguerras, no es lo mismo interpretar el mundo que proceder a su cambio y por lo tanto es menester adecuar y contextualizar el abordamiento que de Marx realiza Valencia Zea en la totalidad de su obra.

16 De otro lado, un perfilamiento tan estrecho de la obra de Valencia Zea, como el realizado por López, desconoce impertinentemente un contexto histórico de avasalladoras condiciones. Al respecto, es necesario precisar que la producción de la obra de Valencia Zea no se limitó de 1945 a 1957.

17 Antes de hablar de las relecturas marxianas, a estas alturas, cabe precisar que los escritos de Marx no eran sistemáticos ni homogéneos, por lo menos en su parte central (Attali, 2007, p. 344); era una filosofía hegeliana del eterno anhelo humano de una sociedad perfecta. Consistían en un análisis del capitalismo, sus tendencias críticas y una esperanza histórica, expresado con una intención profética, sin mayor método. Pero no por ello ha de desconocerse que durante su punto estadístico más alto, un tercio de la humanidad vivió bajo regímenes inspirados en la obra de Carlos Marx con algún grado de éxito político y sin contar con la fundación de partidos socialistas y comunistas en muchos otros países, todo lo cual se realizó en periodos muy cortos, que no fueron tan siquiera de siglos sino de décadas y en algunos casos de apenas lustros o ańos. Así mismo, la conquista de los así llamados derechos sociales, en casi todas las democracias del planeta se ha debido, de una u otra manera, a la filosofía marxista, y su consolidación ha permitido el mejoramiento de las condiciones de vida, de alimentación, educación y acceso a servicios de casi la totalidad de la humanidad en los últimos setenta ańos.

Hoy en día, bajo el análisis renovado de la obra de Marx, resulta claro que el pensador alemán nunca pretendió la fundación de regímenes de estado, ni la imposición de una ideología; como filósofo e historiador, simplemente trató de avizorar lo que consideró que sería el futuro de la humanidad, si continuaba en el marco del capitalismo sin regulaciones y como el mismo Hobsbawm —el historiador más grande del siglo xx, aún siendo marxista— lo menciona: para el ya muy irascible Marx, la simple idea de que bajo su nombre se impusieron regímenes totalitarios atentatorios de la libertad y dignidad del ser humano sería algo tan descabalado como repulsivo. 
Ya para 1945 existía una preocupación académica y iusfilosófica lo suficientemente seria y adecuada, por virtud de la cual los totalitarismos debían ser eliminados de cualquier clase de concepción política: ellos habían causado la peor conflagración conocida por el hombre. A raíz de ello, una significativa apertura de múltiples vías posibles, para lograr ese objetivo, vino a identificar ese periodo de posguerra. Los siguientes veinticinco años vendrían a caracterizarse por la consolidación de un nuevo debate marxista, por tres razones fundamentales y específicas: a) el reconocido avance de la URSS y de otros países socialistas a partir de la década de los cincuenta; b) la redenominación de "tercer mundo" para aquellos países que, habiendo sido colonias de las metrópolis, habían caído en la desindustrialización y extremos grados de pobreza, en particular Latinoamérica; y c) el sorprendente estallido intelectual marxista que puede aglutinarse bajo lo que se denominó en general como "mayo del 68".

Desde 1956 y posteriormente a mediados de los sesenta, en los países desarrollados y en la periferia, respectivamente, los marxistas debieron a regańadientes admitir que los regímenes socialistas existentes desde la URss, China, Vietnam y hasta Cuba, entre otros, estaban lejos de ser lo que ellos mismos habrían deseado que fuese una sociedad socialista o a lo sumo una comunidad dirigida hacia el socialismo (Hobsbawm, 2011, p. 356 $)^{18}$.

Fue precisamente esta mal aceptada necesidad de revisionismo ideológico lo que hizo que la cantidad de escritos marxistas, derivaciones, adecuaciones e impostaciones aumentara enormemente, en la totalidad del globo. Para 1970 prácticamente todos los oponentes del status quo que deseaban reemplazarlo por una nueva forma de sociedad describirían sus programas o meros anhelos en términos de socialismo,

18 Se retornó, o a lo sumo volvió a ser popular, la posición anterior a 1917 que prevenía que el socialismo solo podría nacer legítimamente, en todo el mundo plenamente alienado por el poscapitalismo: así, pretender instaurar por la fuerza el socialismo en países pobres, que parecían apenas haber comenzado a superar formas diversas de feudalismo, había evidenciado algún grado de fracaso práctico, ya en cuanto a la imposibilidad material de instaurar el socialismo per se o en cuanto a los métodos totalitaristas aplicados. Los problemas derivados de la sociedad capitalista exclusivamente (y no otros) eran los que tenían que ser superados por esa forma de comunidad, socialista en ciernes. Esa situación recondujo a que existiera una razón para rechazar no solo el socialismo o el comunismo, sino todo lo que tuviese que ver con el nombre de Marx: el análisis realizado era que a lo único que conducían esos regímenes era o a los gulags de la Rusia de Stalin o a la pena de muerte en la China de Mao; y todo gracias a Marx. Sin embargo, como bien lo anota Hobsbawm (2011, p. 357), semejante conclusión sería como admitir que todo el cristianismo debe reconducir siempre, lógica y necesariamente, al absolutismo papal o que toda forma de darwinismo ha de concluir en la ley del más fuerte, siempre en términos capitalistas. 
dejando sentada en esa afirmación la altísima influencia que en esos planes tenía la ideología marxista. Resultaban, sin embargo, altamente sospechosos los métodos ya aplicados estatalmente para materializar esas ideas, por lo que, además, se hacía menester aterrizar toda la teoría marxista en cada una de las ciencias sociales e incluso en cada ciencia pura.

En ese marco, también surgió la literatura marxista que concentró su atención en las relaciones entre los países dominantes y aquellos en vías de desarrollo ${ }^{19}$. Gunder y posteriormente Wallerstein renovaron esa discusión en términos transnacionales y de alguna manera evidenciaron con cierta rigurosidad epistemológica que empíricamente el capitalismo trasnacional colonialista había tenido el efecto del surgimiento del mercado europeo en la superación del feudalismo, donde los países del núcleo establecieron una explotación sobre los de la periferia ya para el siglo xvi y ello generó una economía capitalista, que como tal debía ser entendida y desarrollada. Consecuentemente, el desarrollo del centro había tenido como costo natural el subdesarrollo de la periferia.

Los intelectuales acogieron tales planteamientos y por contera ante la ausencia de un proletariado mínimamente organizado en los países periféricos, pero en especial en Latinoamérica, era necesario redireccionar la teoría marxiana a la población que pudiera gestar el salto del capitalismo hacia el socialismo. La única población que reunía esas características era el campesinado desposeído ${ }^{20}$.

El necesario progreso agrario, pero además la redistribución de la tierra, posibilitarían entonces la eliminación del mayor obstáculo económico para la formación de

19 La historiografía vino a ser el arquetipo de esta clase de discusión: las hipótesis lanzadas para tratar de evidenciar por qué fracasó el feudalismo y debió ser reemplazado por el capitalismo dejaron de concentrarse puramente en la relación siervo de la gleba - amo de la tierra, para enfocar sus mejores argumentos en el tema del surgimiento del comercio. Dobb y Sweezy fueron los dos principales representantes de una y otra vertiente.

20 Sin embargo, toda la concepción descrita por Wallerstein implicaba una dualidad no resuelta: ‘había que dirigir los cambios contra el mal interno representado por los terratenientes acaparadores de la tierra, que dominaban extensos latifundios atrasados con respecto a las economías agrícolas especializadas y tecnificadas (identificado por Wallerstein con una ulterior forma de feudalismo), o era menester dirigir los ataques teóricos y políticos contra el imperialismo, última fase decadente del capitalismo, materializado por la tarea policiva asumida por parte de los Estados Unidos de Norteamérica que, a su turno, era el motor de avance de esa economía latifundista y atrasada de las burguesías locales de la periferia? (Hobsbawm, 2011, pp. 359-360). 
una clase media burguesa mucho más estable y robusta, conformada por los anteriores campesinos desposeídos: la existente exclusión de masas de campesinado empobrecidas y marginadas de la moderna economía debía ser eliminada. Así pues, más o menos, luego de 1965 se dedicó una cantidad considerable de teoría marxista (y no marxista, o mejor procapitalista) a los problemas agrarios y campesinos ${ }^{21}$. El interés que despertó el tercer mundo entonces fue algo sin precedentes. Fundamentalmente en Francia se desarrolló a profundidad la antropología social marxista en manos de Meillassoux y Godelier, este último prolijamente citado por Valencia Zea en la parte propositiva de su obra.

2. Cabe anotar que al margen de estos desarrollos puramente intelectuales, el proletariado manual no sufrió la involución que Marx predijo, sino que, por el contrario, a instancias de las onerosísimas cuentas pasadas por la peor conflagración conocida por la humanidad a todos los estados participantes, las ayudas, los subsidios, el replanteamiento de las formas de remuneración laboral y en general el welfare state o estado de bienestar planteado por los aliados inicialmente y luego por la gran mayoría de estados europeos, implicaron el mejoramiento del nivel de vida del obrero manual y de su familia, y el acceso a mejores y mayores niveles de educación y salud.

De alguna forma, todo ello recondujo a la distensión del conflicto social, cuyo empeoramiento había sido avizorado por Marx. Las filas marxistas se vieron entonces removidas y renovadas, para dejar de ser proletarias y convertirse en masas de estudiantes e incipientes intelectuales en un movimiento internacional evidente y real a lo largo de 1960, especialmente en Francia e Italia, pero luego también en Yugoslavia, Polonia, Checoslovaquia, México e incluso en los Estados Unidos de América

21 Aricó, sin embargo, postula que ya Marx y Engels habrían tenido incipientes desarrollos sobre la cuestión agraria, que luego serían relevantes en esa década de los setenta, ya descrita (2010, p. 204 y ss.). Sin embargo, a mi juicio, por ejemplo, el prefacio a la guerra campesina en Alemania o el problema campesino en Francia y en Alemania, ambos de F. Engels, antes que tener un abordaje de las problemáticas respectivas, constituían formulaciones programáticas, para inducir al campesinado al ingreso de un partido político correspondiente, a uno u otro lado del Rin.

Sin embargo, la obra monumental de Marx, El capital, es en sí misma una forma de tratamiento minucioso y diferenciado sobre qué es toda forma de propiedad, lo que no solo en esta ponencia discutiría con Bobbio y su afirmación de que los tratamientos jurídicos de Marx (a lo sumo de la propiedad) son muy aislados, sino que además permitiría proponer una revisión de las relecturas de Marx sobre cómo la propiedad del suelo se articula a toda la dinámica de la acumulación de capital. Al respecto, revisar el libro tercero de la parte tercera que se refiere a "El proceso de producción capitalista en su conjunto" (Marx, 1999, III, p. 45.) 
para $1968^{22}$. Los partidos marxistas, socialistas o comunistas, ahora nutridos por el nivel de intelectuales grandes, estaban, sin embargo, en un shock de desorientación, pues por primera vez fueron conscientes de que la predicción de Marx, sobre el triunfo proletario del socialismo, cada vez se alejaba más y más.

Antes que desfallecer, por el contrario, muchos elementos marxistas permearon el lenguaje del discurso público estudiantil, académico y profesoral. Y el marxismo universitario en Latinoamérica se hizo endémico, en tanto que en los países desarrollados si bien fue epidémico nunca dejó de ser fuerte (Hobsbawm, 2011, p. 369). El tradicional vínculo del marxismo con el proletariado evolucionó, si se quiere mutó, en Latinoamérica a una relación con el campesinado, con los estudiantes, pero sobre todo - lo cual vale subrayar aquí-, con los intelectuales y profesores. Incluso esos intelectuales, profesores y universitarios descalificaron abiertamente al proletariado como clase revolucionaria. Herbert Marcuse se constituyó en el principal adalid de esa filosofía, en especial en su obra El hombre unidimensional, de 1964.

He tratado de presentar muy concretamente cómo el marxismo se transformó en academia en dos sentidos, postulados parcialmente por Hobsbawm (2011, p. 369 y ss.). Por un lado, tenía como público destinatario a estudiantes pasados, presentes y futuros, que debían articular alguna clase de revolución socialista desde distintos niveles, estamentos o frentes; $y$, por otro lado, creó un lenguaje altamente complejo, casi esotérico, no accesible a los no académicos y, en parte por ello, desembocó en discusiones altamente teóricas. Así, Althusser, Lukacs, Camus, Sartre, en parte Bobbio y Poulantzas dedicaron su entendimiento del marxismo - que, entre otras cosas, dio por tener a El capital como una especie de forma epistemológica o propedéutica - a discursos particularistas de sus ciencias o artes y los especificaron hasta niveles que incluso los hicieron inaccesibles ya por teóricos, ya por inaplicables, ya por abstractos.

22 La segunda y la tercera internacional estuvieron integradas fundamentalmente por las clases proletarias europeas. A finales de los cincuenta el marxismo pasó a integrarse abrumadoramente por intelectuales que ahora constituían un importante y amplio frente social. Aunque la verdad es que el lesender Arbeiter u obrero lector descrito por Bertold Brecht no fue nunca una realidad, sino en un par de regiones de dos o tres países. 
Lo que se consolidó en los años setenta fue, entonces, una cultura marxista dentro del capitalismo cosmopolita e informal, pero en parte pendenciera por un lado; e increíblemente teórica por el otro. Incluso, en ese contexto comenzaron a surgir autores marxistas locales: desconocidos fuera de su país de producción, pero que eran claramente identificables bajo todos o algunos de los parámetros aquí descritos. Esos autores tendían a ser influyentes, como particulares no comprometidos, intelectuales que generaban libros, artículos y lecturas marxistas al interior de sus países: Althusser, Marcuse, Sartre, Colleti, más tardíamente Habermas (Mejía, 2013a, p. 85 y ss.) o incluso el mismo Hobsbawm, y en otra perspectiva Lévi Strauss o Lacan podrían ser allí enumerados.

3. Fue en esa época que escribió Valencia Zea su obra, entre 1945 y 1990, cuando los epígonos nacionales y locales de Marx desarrollaron respuestas metodológicas para obtener de manera temprana la transición entre un deforme capitalismo y un embrionario socialismo que cambiara los destinos de la humanidad: en ese sentido, los autores más citados por Valencia Zea en perspectiva, en la parte propositiva de su obra, son Marx, Engels y Hegel. A pesar de la importancia que encierran los nichos o las frecuencias citacionales, y las asimilaciones propedéuticas o metodológicas propias de la teoría jurídica, lo más relevante para mí es que sin conocer a Valencia Zea, la descripción que hace Hobsbawm sobre las meticulosas tareas de los intelectuales marxistas locales parece acoplarse de manera precisa a su rigurosa obra, tal como encajaría un molde a su escultura: Valencia Zea fue un académico, profesor de derecho y doctrinante jurídico, que sintiendo una comunión casi absoluta con la filosofía marxista, y siendo consciente de la previsión histórica, según la cual se debería prescindir de innecesarios tiempos de capitalismo que llevaran a extremos insospechados la pobreza del campesinado periférico, dirigió sus revaluaciones metodológicas y propositivas hacia los problemas de la dialéctica periférica, hacia el problema de los desposeídos latinoamericanos, necesitados de una o de muchas reformas agrarias y los analizó adecuando las teorías marxistas al derecho: en especial al derecho de posesión y propiedad. Por supuesto, la diferencia con otros intelectuales yace en que las teorías de Valencia Zea fueron dogmática y programáticamente útiles al país, como ya se verá.

Convencido de equiparaciones consecuentes entre capitalismo e imperialismo, entre feudalismo y expoliación internacional, dedicó entonces, como bien lo denotan sus 
referencias a Maurice Godelier, sus estudios a la antropología social (Valencia, 1982, pp. 232-233) y por esa vía a la cuestión agraria, no para describirla simplemente, sino para encontrarle solución por vía de la posesión, como método propiciado por Hegel para acceder de manera inmediata, si se quiere ipso facto, a la propiedad, y que permitiera titular a favor de los desamparados la tierra, que para superar sus necesidades, justamente se habían visto obligados a explotar. En estas latitudes, la creación de una suficiente burguesía no tenía que ver con un proletariado explotado, sino con brindarle soluciones a un campesinado desposeído. Era menester entonces dedicar sus esfuerzos a la comprensión de la posesión como método ${ }^{23}$, para modificar como objetivo final la noción de propiedad capitalista, y en ese sentido modificar los internalizados conceptos de uso, goce, disposición y sobre todo abusus, que tanto daño hacían a los alienados juristas clásicos ${ }^{24}$.

\subsection{Los profesores y el círculo académico de Valencia Zea}

Respecto del contexto académico, resulta necesario recordar puntualmente a Rubén Sierra y a Rubén Jaramillo (1986, p. 201 y ss.), quienes nos ponen de presente la filosofía urbana, proletaria y campesina que le permitió liberarse de los clásicos cánones teológicos y que comenzaba a invadir el país, o, para ser más preciso, que hervía en el naciente campus de la Universidad Nacional de Colombia. Jaramillo menciona que la Facultad de Filosofía se derivó de la Facultad de Derecho y que esa situación implicó una circunstancia sintomática, derivada de la cruenta época mundial de la primera maduración reflexiva de aquellos nacientes filósofos: "el ascenso del fascis-

23 Por supuesto, Valencia Zea conocía los tratamientos dogmáticos que sobre la posesión habían sido realizados tanto por Savigny como por Ihrering, pero atribuir los fundamentos teóricos de la obra de Valencia a esos dos juristas también implicaría un equívoco; pues en principio el abordaje de esos autores es puramente de perfeccionamiento dogmático y, por otro lado, las aproximaciones que hace Valencia Zea a la posesión y a la propiedad son esencialmente críticas; si se quiere con una pretensión modificatoria, en la parte propositiva de su obra.

24 Baste recordar que el artículo 669 del Código Civil Colombiano disponía que "El dominio (que se llama también propiedad) es el derecho real en una cosa corporal, para gozar y disponer de ella arbitrariamente, no siendo contra ley o contra derecho ajeno". La palabra "arbitrariamente" fue declarada inexequible por la Corte Constitucional mediante Sentencia C-595-99 del 18 de agosto de 1999.

A su turno, el $\$ 903$ del Código Civil alemán preceptuaba originalmente: "El propietario de una cosa, puede, en la medida en que la ley o derechos de un tercero no se lo impidan, obrar con la cosa, como bien le parezca y excluir a otros de cualquier afectación". Por supuesto, luego de 1949, tanto el Tribunal Supremo Federal como el Tribunal Constitucional Federal han mitigado la amplitud con que el propietario podía "abusar" de la cosa. 
mo europeo, la guerra civil española, la segunda guerra mundial. Una preocupación práctica tenía necesariamente que impregnar la actitud de (las) personas [...] porque lo que estuvo en juego entonces fue el destino mismo de la civilización”25.

\begin{abstract}
Ahora bien, pareciera también necesario evidenciar la coherencia estudiantil y profesional de Valencia Zea con la totalidad de su obra. Atravesó la carrera de derecho junto a un compañero de pupitre, que luego se convirtió en su compañero de oficina, Enrique J. González, y tuvo a grandes profesores, desde Jorge Eliécer Gaitán, hasta Gerardo Molina; y desde Luis Felipe Latorre ${ }^{26}$, hasta Juliot de Lamorandiere en Bogotá. Valencia Zea dominó tempranamente la dogmática civilista y fue por supuesto
\end{abstract}

25 “[...] En el año 1946 (se da) la fundación de la facultad de Filosofía y Letras de la Universidad Nacional, en donde se agruparon unos cuantos investigadores y maestros que ya laboraban en las cátedras de la facultad de Derecho. [...] Los fundadores de (esa) academia fueron el maestro Cayetano Betancourt, [...] el maestro Rafael Carrillo Luque, [...] el maestro Danilo Cruz Vélez, [...]. Debe mencionarse además el papel que desempeńara el doctor Rodrigo Jiménez Mejía, [...], quien como decano de la Facultad de Derecho creó las condiciones y propició ampliamente la fundación de nuestro Instituto de Filosofía, siendo rector del Claustro el maestro Gerardo Molina.[...]. [S]ería injusto olvidar el aporte de otros intelectuales como Luis Eduardo Nieto Arteta y Julio Enrique Blanco.

“[...] El proceso de urbanización, la industrialización, que se acelera en los años treinta y cuarenta, la migración masiva a los centros urbanos y la formación de un proletariado que ya cuenta por entonces con dirigentes como María Cano, Ignacio Torres Giraldo y Raúl Mahecha, todo ello acompańado por el eco de acontecimientos universales como los que hemos reseńado, es lo que va a definir la circunstancia que propicia en Colombia el surgimiento de una primera generación de filósofos". "[...] la filosofía” constituyó "también un factor de integración” y se ha de "considerar con gratitud de qué manera ha contribuido a forjar lo que ya se ha dado en llamar nuestra 'personalidad histórica', algo de lo que constituye nuestra nacionalidad, nuestra manera de ser. Acaso podamos felicitarnos de que ello sea así, [...], porque el intelectual, como pensaba Antonio Gramsci desde la cárcel, no quiere ser otra cosa que el filósofo democrático, un compańero de ruta en el proceso de la liberación" (Jaramillo, 1986, pp. 211-214). Al respecto también puede consultarse a Rubén Sierra Mejía cuando se refiere a la ruptura definitiva de la filosofía colombiana en la década de los cuarenta, con la tradición neotomista, a través la aparición de tres obras específicas de Luis Eduardo Nieto Arteta, Rafael Carrillo y Danilo Cruz Vélez (1978, p. 144 y ss.), que además van a ser autores significativos a la hora de comprender la cercanía de Valencia Zea con la naciente Facultad de Filosofía de la Universidad Nacional, para la misma época. En el caso específico de Carrillo (1947, p. 47 y ss.), la recepción y acomodamiento de las teorías kelsenianas en Colombia.

26 A quien Valencia Zea consideraba el más grande jurista del siglo xx no solo por su sistematicidad, sino por haber redactado la Ley 28 del 32 que otorgó igualdad formal de derechos a hombres y mujeres en Colombia y por haber trabajado incansablemente por una jurisdicción de familia y una verdadera igualdad material de la mujer y en contra de las discriminatorias clasificaciones legales de hijos (no es verdad, por lo menos hasta donde se puede verificar, que sintiera gran admiración por Eduardo Zuleta Ángel, como en varias oportunidades he escuchado, pues aunque fue su profesor, nunca refirió nada al respecto en las oportunidades que tuvo). (Cfr. Arturo Valencia Zea, El hombre, el jurista, 1995, p. 15 y ss.). Con pertinencia para esta ponencia, recuérdese que Latorre impulsó tres (algunos hablarían de cuatro) leyes específicas: la incorporación en el código judicial de un juicio sobre declaración de pertenencia, una de modificación del registro y matrícula sobre la propiedad inmueble (otra sobre 
consciente de la necesidad de superar a Fernando Vélez, se familiarizó con la doctrina chilena, española y francesa y es evidente que sobre la mitad de los ańos cincuenta tuvo un giro germanista, más no puramente kelseniano ${ }^{27}$.

Se puede afirmar, sin temor a equívocos, que Valencia Zea fue un hijo de su tiempo, que de 1945 a 1990 dedicó su preclaro talento de doctrinante, no solo a la relectura y análisis del derecho civil comparado, como lo sugerían los más estrictos cánones, delimitados, por ejemplo, por Rene David, citado de manera adelantada y vanguardista en su obra; sino que fue un humanista de considerable relevancia; $y$, por consiguiente, agotó el estado del arte de la sociología y la filosofía de la historia como bien nos lo permite concluir la más sencilla verificación de su nicho citacional, como ha quedado postulado.

\section{Parte propositiva de la obra de Valencia Zea}

Ahora bien, continuando con el ejercicio, vale anotar que la obra de Valencia Zea se compone de su Derecho civil, que cuenta con seis tomos: parte general y personas, bienes, obligaciones, contratos, familia y sucesiones. Esta división del abordaje del derecho civil obedece a influencias claramente francesas del siglo XIX (se pueden encontrar obras idénticamente divididas y tituladas, así como alemanas del siglo xx, solo por mencionar un par: Planiol, Ripert y Boulanger o Enneccerus, Lehmman - Enneccerus, Kipp, Wolf). Adicionalmente, existen tres obras magistrales, mucho menos dogmáticas y más propositivas en términos de técnica legislativa, de derecho comparado y de filosofía de la historia, respectivamente: su Proyecto de Código de Derecho Privado, su obra La posesión y, por último, —mi favorita, Origen, desarrollo

prescripciones civiles) y una última sobre el régimen de las casas y granjas para empleados y obreros (Latorre, 1937, p. 27 y ss., 85 y ss., 165 y ss. y 211 y ss. respect.).

27 Valencia Zea litigó inicialmente en lo que para entonces comenzaba a perfilarse en Colombia como un incipiente derecho laboral junto con el también profesor Enrique J. González: en los contenidos de la Ley 10 de 1934, que además se estudiaba en una materia llamada "derecho social" que Valencia visitó con el maestro Gerardo Molina. (Cfr. Arturo Valencia Zea, El hombre, el jurista, 1995, p. 15 y ss.). Creada posteriormente la jurisdicción laboral, permaneció Valencia en los terrenos del puro derecho civil, pero siempre bajo una visión crítica y eminentemente social. 
y critica de la propiedad privada ${ }^{28}$. De manera sopesada, debería por lo mismo determinarse cuál es la parte de la obra que merece cualificarse de propositiva y al respecto vale anotar que el tomo de Derechos reales, La posesión y Origen, desarrollo y critica de la propiedad privada componen el corpus propositivo de Valencia Zea, pues son los volúmenes en los que se halla expuesta la concepción filosófica y teórica del tema que más tiempo y esfuerzos demandó del autor: esos textos contendrían el arquetipo propositivo de su obra: la posesión, la propiedad privada y su necesidad de modificación.

\subsection{TOMO II, DERECHOS REALES: DOGMÁTICA CRÍTICA}

Llama tempranamente la atención del lector que en el tomo segundo de su obra Valencia Zea incluya críticas, de diversos órdenes — cristianas, socialistas utópicas y hasta marxistas como tales consideradas-, a la propiedad privada, luego de desarrollar su concepción puramente jurídica. Esa inicial e incipiente tarea que a lo largo de las sucesivas ediciones del mismo tomo se fueron decantando, enriqueciendo y profundizando, parecieran ser el acicate certero para escribir los dos libros complementarios de su obra ${ }^{29}$.

Allí mismo, a través de un desarrollo completo del régimen agrario en Colombia, supera a Simón Carrejo, a Antonio Rocha, a J. J. Gómez, a Honorio Pérez y a Guillermo Amaya Ramírez en completitud, claridad, rigurosidad descriptiva e histórica y por supuesto en propuestas sobre lo que debería haber ocurrido con la jurisdicción agraria. Incorpora un crítico análisis de los antecedentes históricos de la Ley 200 de

28 Una verificación iusteórica implicaría entonces determinar los nichos citacionales, ojalá no jurídicos sino preferiblemente filosóficos, económicos, sociológicos, antropológico-sociales y, por supuesto, teóricos en estricto sentido de la parte propositiva de la obra de Valencia Zea. Esta tarea incluso puede ser realizada de una manera muy sencilla, pues la misma editorial Temis los integró al final de cada uno de los tomos de la obra, siguiendo la moda europea de incorporación de los índices onomásticos paginados. El nacimiento y fortalecimiento de esa editorial guarda, en el imaginario colectivo de muchas generaciones del estudiantado de la Facultad de Derecho de la Universidad Nacional de Colombia, hasta tal vez, la mía propia, un simpático paralelismo; si se quiere, una simbiosis extrańa, con la obra de Valencia Zea, Luis Carlos Pérez, Guillermo González Charry y otros muchos profesores de la Facultad de Derecho de la Universidad Nacional, que siempre se autorreconocieron, de una $\mathrm{u}$ otra forma, como marxistas.

29 Esto es, aparte del Proyecto de Código de Derecho Privado: La posesión y el Origen, desarrollo y crítica de la propiedad privada. 
1936, desde las titulaciones coloniales hasta la desamortización de bienes de manos muertas; postula su incomprensión de una inútil reforma agraria en el siglo XVIII, y así mismo, de manera crítica, expone las razones legislativas de la Ley 200 de 1936 y de la Ley 135 de 1961, junto con el Decreto 2303 de 1989, haciendo gala de un ejercicio de materialismo dialéctico local interesante.

Su visión panorámica sirvió de fuente principal a las relecturas actuales sobre la concepción de la propiedad, pues a pesar de que hoy en día se quiere hacer ver de manera artificiosa una modificación constitucional históricamente progresiva, a lo largo del siglo xx; lo cierto es que fue a nivel legal que se produjeron la secuencia de cambios más significativos. Actualmente, en efecto, luego de teorizar sobre la constitución, los marcos normativos agrarios específicos, se evidencian, por fuerza, como elementos puramente legalistas (Alviar, Villegas del Castillo, 2012, pp. 17 y ss. y 33 y ss.).

\subsection{LA POSESIÓN Y Hegel: EL ZEITGEIST DEL DERECHO COMPARADO $^{30}$}

En su obra La posesión, Valencia Zea hace un estudio de derecho comparado que da cuenta de las similitudes del instituto en las más diversas latitudes y sistemas jurídicos, desde el clásico continental europeo hasta el soviético de la época, practicado en la Unión de Repúblicas Socialistas Soviéticas. Semejante estudio no tiene nada que ver con formalismos o modas pasajeras. Valencia Zea, conocedor profundo de la obra de Marx y Hegel, así como de Weber y Durkheim, no adopta como opción de profundización propositiva de su obra el instituto de la posesión de manera arbitraria o desapercibida, sino por razones que daban cuenta del estado del arte de la discusión marxiana sobre Latinoamérica.

30 A este respecto y como bien refiere Attali: "Para [Hegel] los individuos, formas de expresión de la libertad, sin quererlo ni saberlo, están al servicio de la Historia por lo que él llama una 'astucia de la razón'. El papel del Estado, entidad ideal y absoluta, por encima de la Historia, es permitir que cada uno disponga de lo que es necesario para vivir 'decentemente', velar porque 'nadie esté privado de ello, nadie haga un uso abusivo', y poner fin a los conflictos. Al término de la Historia desaparecerá la 'alienación', que para Hegel es, a la vez, Entfremdung y Entäusserung'. (Énfasis ańadido) (Attali, 2007, p. 33). Véase también Hegel (1983, p. 122 y ss.), sobre autoridad y libertad. 
Valencia Zea, quien simpatizó abiertamente con ideas comunistas en una parte de su vida (Cfr. Valencia Zea, El hombre, el jurista, 1995, p. 15 y ss.), aborda el tema de la posesión para Colombia, en un contexto determinado que se integraba por una serie de reformas agrarias ocurridas o pendientes a lo largo y ancho de América Latina, a partir de los años sesenta y hasta bien entrados incluso los ańos ochenta. Pero además, bajo otro contexto, que para un científico social de su rigurosidad era claro y por demás agobiante, la Ley 200 de 1936 había sido inaplicada luego del Frente Nacional. Es reconocida por toda la academia dedicada al tema, una contrarreforma, que iba a perpetuar las desigualdades desproporcionadas en nuestro país a nivel de posesión y sobre todo propiedad de la tierra, como fuente de riqueza agraria (Kalmanovitz y López, 2006, p. 13 y ss.).

Valencia Zea para nada fue un positivista miope, como quieren hacerlo ver. Fue un crítico profundo de la propiedad privada como forma de alienación que impedía el básico desarrollo humano y preveía e intuía que la solución a esa concepción de la propiedad podría lograrse a través del afianzamiento de la posesión como instituto de reparación última o de reemplazo. Así mismo, percibió que la retrógrada concepción de la propiedad, por él criticada, era la principal causa del gran conflicto social existente en nuestro país y que estaba relacionada precisamente con la solución de subsistencia para los desposeídos, para aquella franja de población que no pudo acceder a los mínimos medios de subsistencia por una perversión misma del modelo económico, patrocinado a su vez por un sistema republicano encubridor y acomodado. Verdadero académico comprometido y propositivo, con un profundo conocimiento de la historia del país y del contexto del conflicto, se permitió advertir que tanto la perpetuación como la finalización del conflicto tendrían que ver, en esencia, con la titulación de tierras poseídas por los campesinos, que sin ninguna clase de título concurrían a trabajarlas.

Los problemas que se resuelven hoy a través de la ley de reparación de víctimas, la ley de restitución de tierras, la inversión de la carga de la prueba ${ }^{31}$, la concepción de la tierra como un medio que brindaba recursos para subsistir y no como un fin de acaparamiento y especulación, la explotación agrícola o ganadera del suelo como causas

31 Ley 975 de 2005, en concordancia con la Ley 1592 de 2012; la Ley 1448 de 2011, los decretos ley 4633, 4634 y 4635 . 
suficientes para el acceso a la titulación y a la propiedad, fueron problemáticas avizoradas, y en gran parte tratadas y resueltas por Valencia Zea en esa parte propositiva de su obra; pero, fiel a su tarea de jurista íntegro, la dedicó a la reconceptualización tanto de la posesión como de la propiedad en términos multidisciplinarios pero con un foco y soporte jurídico de inmensas dimensiones.

Semejante labor tenía además, por supuesto, una fundamentación teórica portentosa: es evidente su juiciosa lectura de Hegel a lo largo de toda su obra, que agota el estudio del derecho civil desde aquel Zeitgeist, un tanto pesimista, un tanto nostálgico, que permitía entrever que el Estado de derecho era (sería/debería ser) la única solución plausible al conflicto social en nuestras latitudes (Acosta, 2008, p. 173), y que la compenetración de las normas en los sujetos permitiría la verdadera juristische Frieden o paz jurídica derivada del ethos $^{32}$ pregonado por Hegel en su Filosofía del derecho $o^{33}$. Pero además, al agotar de manera comparada el tema de la posesión, Valencia Zea pareciera estar culminando simultáneamente dos tareas: por un lado, verificar que la noción de posesión moderna implicaba en su tratamiento legal o jurisdiccional un amparo inmediato (no luego de cierto tiempo), una forma de ethos universal, que por vía del acoplamiento de las costumbres debería permitir a los gobernados por el código de Bello ${ }^{34}$ perfeccionar su comprensión y por ende plegarse a esos mismos tratamientos, prácticamente inmediatistas en el reconocimiento de derechos, por la

$32 \$ 150$ de la Filosofía del derecho de Guillermo Federico Hegel: "Lo ético (ethos) que se refleja en el carácter individual como tal y determinado por la naturaleza, es la Virtud. La honestidad es la Virtud que no presenta sino la mera adaptación del individuo a los deberes de las relaciones a las cuales pertenece".

$33 \$ 44$ de la Filosofía del derecho de Guillermo Federico Hegel: "La persona tiene, para su fin esencial, el derecho de poner su voluntad en cada cosa, la que, en consecuencia, es mía; no teniendo aquella en sí misma un fin semejante, retiene su determinación y anima mi voluntad; el absoluto derecho de apropiación del hombre sobre todas las cosas".

34 Sobre la evolución del Código Civil Chileno como tal, ver, entre otros: Somarriva Undurraga. Al respecto, de manera concreta, vale anotar que son mínimas las adecuaciones. Sin embargo, es interesante por ejemplo el desarrollo chileno, entre otros, sobre el traslado de las acciones posesorias al régimen de aguas; pero más aún, toda la readecuación legislativa de esa materia. En nuestro país el agua ha sido, desafortunadamente descuidada de manera total, por el derecho civil contemporáneo (Somarriva, 1983, p. 330 y ss.). A su turno, Valencia Zea manifiesta de manera progresiva, en las sucesivas ediciones de su primer tomo, cómo ha evolucionado el Código Civil Colombiano, a nivel legislativo y jurisprudencial; y allí —itero- las doctrinas de la Corte Dorada de 1936, contrariamente a lo sostenido por López, son una constante, también progresivamente desarrollada: véase, ejemplificativamente en la última edición en solitario del tomo primero las páginas 52 y siguientes, donde se continúa nombrando a los integrantes de esa "Corte dorada” y se exponen sus más notorios desarrollos en 1936. (Valencia, tomo primero, 1989, pp. 52-54). 
simple verificación de un beneficio para el poseedor ${ }^{35}$; y, por otro lado, dio verdadera fuerza a una noción que no parecía tan clara en Colombia. En efecto, él junto con J.J. Gómez en sus obras Derechos reales y Bienes, respectivamente, pero sobre todo en La posesión, afianzaron la tímida creencia cierta de que quien explotaba un bien merecía acceder a todas las diversas formas del amparo posesorio inmediato y a la propiedad de este, no por una razón ideológica ni política, sino más por una razón histórica, desprendida del derecho romano, y consolidada tanto por el sistema continental ${ }^{36}$, el sistema del common law, el derecho oriental y el soviético, pero que además, y he allí su propuesta, debería potenciarse para acceder a una verdadera justicia social y a una igualdad material, efectiva e inmediata de los asociados.

Este trabajo da cuenta de que previamente Valencia Zea propició enjundiosas discusiones $^{37}$ y consolidó posteriormente inteligentes convencionalismos, pero solo para seguirlos precisando y decantando, como le corresponde al eterno dogmático juicioso. Así, se citó durante muchos lustros a Valencia Zea en muchísimos despachos judiciales: "son poseedores todas las personas que según los usos sociales explotan económicamente las cosas en provecho propio a semejanza de los propietarios”. $\mathrm{O}$ "buena fe es la confianza, seguridad y honorabilidad en la conclusión de nuestros actos y en el ejercicio de nuestros derechos" ${ }^{38}$. Por lo demás, no sobra referir que el efecto certero de su comprensión y exposición agotadora de la posesión permitió, de alguna manera, que muchos poseedores pudieran, en especial a través de los artículos $1^{\circ}$ y $2^{\circ}$ de la Ley 200 de $1936^{39}$ — tema también agotado por Valencia en su tomo

35 Esto es, si se quiere, sin necesidad alguna de procesos de pertenencia o de adjudicación.

36 Así por lo menos, entre otros, Alemania, que ha regulado de manera minuciosa la relación propietario poseedor, en el afán de proteger al poseedor aparente (Medicus, Petersen, 2011, pp. 275-276).

37 Superando algunas nociones imprecisas de Milciades Cortes, de Miguel Arteaga, o incluso de Alessandri Rodríguez, en materia de bienes.

38 Es llamativo el acopio de las citaciones (e incluso paráfrasis) que hace la Corte Suprema de Justicia de los dos mencionados autores, en especial, luego de la expedición del Código de Procedimiento Civil de 1970, a través de los decretos 1400 y 2019 de 1970, en los que otro juicioso jurista, reconocido internacionalmente, Hernando Devis Echandía, dejó su impronta de gran procesalista, a través de su admirable técnica legislativa, para otorgarle vigor a unas letras del Código Civil que pareciera que habían estado aletargadas, casi muertas al conjugarse con la Ley 105 del 31 o Código Judicial (nótese que en esa ley no existía una regulación específica para el proceso de pertenencia, solo existía un capítulo para los asuntos posesorios. Título XXVIII).

39 Artículo. 1.- Modificado, Artículo. 2, Ley 4 de 1973. Se presume que no son baldíos, sino de propiedad privada, los fundos poseídos por particulares, entendiéndose que dicha posesión consiste en la explotación económica del 
segundo- acceder a ser propietarios de las tierras explotadas ( $\$ 101$ del Tomo II, Derechos reales), lo que de por sí implicó un significativo aporte a la justicia social de este país. Hablando precisamente de la posesión, Valencia mencionó, en uno de los apartes más críticos de su obra, así titulada:

[un] motivo del estancamiento científico de una institución jurídica se debe al hábito de trabajar en forma exclusiva con los materiales que suministra un determinado derecho positivo. Cuando una nación es celosa de sus instituciones jurídicas, estas, por fuerza de las cosas se conservatizan, pues se piensa que toda evolución ha terminado, que nos encontramos ante un sistema cerrado; no se tiene, entonces, el cuidado de ensayar una nueva crítica para examinar si sus fundamentos son prácticos, si corresponden o no a la realidad. Efectivamente, si partimos de la idea de que el derecho de tal pueblo es perfecto, el jurista se preocupa, entonces, de explicarlo en la forma más congruente; sus reglas o postulados, se tienen a priori como perfectos y no se advierten sus vacíos o contradicciones lógicas; en fin, la mente del jurista se deforma. Con entendimientos deformados es imposible cualquier investigación que merezca el calificativo de científica. (Valencia, 1978, p. 490)

Por último, luego de un estudio comparado y agotador de 492 páginas, sobre la posesión como institución, Valencia Zea ofrece una noción de posesión que hace gala de la sencillez y rigurosidad, de que solo se pueden servir los grandes maestros, agotadores de la esencia, así: "Posesión es el poder de hecho sobre una cosa que supone una dominación de la voluntad sobre la misma”. Así mismo, teniendo por superada, más no abolida la posesión romana, anota de manera conclusiva: "Lo importante, pues, es que el derecho moderno ha conquistado definitivamente este principio elemental:

suelo por medio de hechos positivos propios de dueńo, como las plantaciones o sementeras, la ocupación con ganados y otros de igual significación económica.

El cerramiento y la construcción de edificios no constituyen por sí solos pruebas de explotación económica pero sí pueden considerarse como elementos complementarios de ella. La presunción que establece este artículo se extiende también a las porciones incultas cuya existencia se demuestre como necesaria para la explotación económica del predio, o como complemento para el mejor aprovechamiento de este, aunque en los terrenos de que se trate no haya continuidad o para el ensanche de la misma explotación. Tales porciones pueden ser conjuntamente hasta una extensión igual a la mitad de la explotada y se reputan poseídas conforme a este artículo.

Artículo. 2.- Se presumen baldíos los predios rústicos no poseídos en la forma que se determina en el artículo anterior. 
toda relación material voluntaria del hombre con las cosas debe ser protegida jurídicamente contra los atentados provenientes de los demás”. ${ }^{40}$.

\subsection{ORIGEN, DESARROLlO Y CRÍTICA DE LA PROPIEDAD PRIVADA: CAMBIAR EL MUNDO Y LA CONCEPCIÓN DE LA PROPIEDAD PRIVADA DESDE EL MATERIALISMO HISTÓRICO DE MARX}

Coherente y riguroso con su pensamiento y su autoformación sociológica, listo su trabajo sobre La posesión en el año de 1978 y en cuyas líneas, "El trabajo de derecho comparado", escrito como un prefacio a una verdadera labor filosófica sobre el tema, es juicioso y preciosista (Cfr. Valencia Zea, El hombre, el jurista, 1995, p. 15 y ss.), abordó, entonces, Valencia Zea la confección y publicación de el que para mí es su más propositivo texto: Origen, desarrollo, y critica de la propiedad privada. Tan solo al escuchar el título de la obra ya no es necesario hacer ningún esfuerzo para identificar, en su esencia, una especie de aplicación localista de un materialismo histórico periférico, como lo califica Hobsbawm en sus apreciaciones, pero no por ello menos preciso o de menor significación descriptiva y académica ${ }^{41}$.

Valencia Zea, convencido de la corrección del canon postulado en la décima primera tesis sobre Feuerbach, confeccionó una visión bibliográficamente diversa y profunda de lo que debía ser una lectura en parte previsora, en parte contestataria latinoamericana de la propiedad, si se quería lograr un salto a una forma novedosa del instituto. Introduciendo la visión corregida del leninismo, propuso una propiedad socialista en

40 Y visionario, como todo agudo académico, predijo, al referirse a la decadencia de la usucapión como instituto que, "el derecho moderno se mueve en el sentido de crear modos directos de constitución y prueba de la propiedad mueble e inmueble, tomando como guía para la primera, la simple posesión adquirida de buena fe y para la segunda, la inscripción en los libros de registro inmobiliario. Y cuanto se diga de la propiedad, debe entenderse correlativamente de los demás derechos desmembrados de la misma”.

41 En ese marco, huelga reconocer que como le ocurrió a los intelectuales marxistas de las metrópolis, los de nuestra periferia tomaron con ahínco la décima primera tesis sobre Feuerbach "hasta ahora los filósofos sólo han interpretado el mundo: la cuestión es cambiarlo" propuesta por Marx y Engels (en su edición final de 1888) y esa especie de teorema y de mantra intelectual, como lo hemos dicho arriba, implicó la aplicación de las lecturas de ese materialismo histórico decantado por más de setenta ańos desde la muerte de Marx, a cada una de sus artes y ciencias, con el ánimo de proponer los mecanismos y las filigranas que, como las maquinarias perfectas de un reloj, deberían propiciar poco a poco la inevitable llegada del incipiente socialismo poscapitalista. 
las sociedades primitivas justificadas en los diversos periodos de la prehistoria ${ }^{42}$. Siguiendo discursos de Germán Arciniegas, que llamaron profundamente su atención (Valencia Zea, El hombre, el jurista, 1995, p. 15 y ss.), y de Guillermo Hernández Rodríguez, se atrevió a describir entre otros a los chibchas y a los incas, para adjudicarle a sus estirpes uterinas, cognaticias y matronímicas, en una tímida y respetuosa visión de la disciplina histórica, una forma de propiedad comunitaria y socialista. Y sus citas de Freyle y Goldenwiser sobre la demostración de la existencia de propiedad privada sobre bienes muebles, entre los chibchas, en la época de la conquista, evidenciadas por la tentativa de prolongar esa pertenencia individual, más allá de la muerte y probada con las excavaciones de sus tumbas; y la ausencia de prueba sobre la propiedad individual de la tierra, dejan entrever el talante investigativo, preciso, analítico, riguroso e innovador de Valencia Zea (1982, p. 77).

Luego de referir la aparición de la propiedad privada, se ocupa de sus vicisitudes en las civilizaciones egipcia, mesopotámica, asiria, hitita, fenicia, cananeo-israelita, medopersa, hindú, china, micénica, griega y, por supuesto, romana; para luego centrar sus análisis en las causas de una concentración estatal medieval de la propiedad y de su salto a una civilización industrial, desde la esclavitud al feudalismo, del capitalismo al imperialismo.

Sin embargo, reduciendo el discurso al estado del arte de la discusión, citado en este escrito arriba y precisado principalmente por Hobsbawm, Valencia Zea evoca con precisión el sistema colonial y las que en los años setenta se delimitaron como sus funestas consecuencias: el imperialismo y los países dependientes, la división y especialización internacional del trabajo, así como la explotación de materias primas por capitales extranjeros.

Finalmente hace una revisión de las propuestas críticas de la propiedad para focalizarse en las del socialismo utópico y, por último, en las del marxismo. La parte sexta de la obra está dedicada a las reflexiones sobre la futura organización económica de

42 Pero como es sabido, la corrección científica posterior ha demostrado que no existía en la prehistoria una noción tan siquiera similar de lo que se considera propiedad o dominio hoy en día. El capítulo quinto de la obra previene, sin embargo, sobre el estado del arte de las capacidades reflexivas del hombre primitivo y su incipiente visión gregaria. 
los pueblos en una aproximación que da cuenta de los cánones del marxismo anterior a la Primera Guerra Mundial, eminentemente profético y descriptivo. El direccionamiento histórico es evidente en esta parte de la obra de Valencia Zea, quien en sus reflexiones finales evidencia la estrecha relación que desde tiempos inmemoriales ha existido entre las nociones de justicia y propiedad, y desde las lecturas de Garaudy, Scheler ${ }^{43}$ y Fromm (pp. 459 y 465) reivindica la alienación del hombre por el concepto de propiedad privada romana y decimonónica. Con una visión futurista, para la época en la cual escribe, Valencia Zea plantea la necesidad de limitar la propiedad de los medios de producción, de los monopolios, de los grandes consorcios, pero no para defenestrar la propiedad privada individual, a la que reconoce como instituto irremplazable, sino para que el Estado pueda obtener los medios necesarios para desalienar al hombre: brindarle los medios básicos para su subsistencia, su supervivencia, su aculturación y su educación; y eso no es otra cosa, lo que ocho años y medio después quedó postulado en la Constitución Política de 1991 bajo la función social y ecológica de la propiedad, pero también bajo los así llamados derechos económicos, sociales y culturales. El derecho a la vivienda digna, el derecho a una justa remuneración por el trabajo, la concepción del crédito como un bien público de cualquier ciudadano, el acceso pleno a la salud y a la posibilidad de disfrutar de una vejez remunerada, el acceso a una educación de calidad, la posibilidad de hacerse parte de la cultura en términos constructivos de participación, el derecho a la diferencia con la implicación de poder tener la suficiencia económica para no desaparecer, como podría ocurrir con muchas de nuestras comunidades indígenas. La lista de derechos derivada de la reconceptualización de la propiedad en términos de materialismo histórico, en términos de redireccionamiento de la plusvalía y la superación del reinado del capital por el capital mismo, de la era victoriana, sería muy extensa ${ }^{44}$.

43 No sobra aclarar que fueron las lecturas desde Scheler, entre otras, en los ańos cuarenta, las que perfilaron una lectura axiológica latinoamericana y sobre todo colombiana de la teoría pura del derecho, pero además desde Garaudy pareciera que se asume por Valencia un marxismo ético y responsable (Carrillo, 1947, pp. 47-83). Confrontar, a su vez, esas lecturas con Garaudy (1966, pp. 47-50).

44 La propiedad colectiva, cooperativa, indígena, intelectual (en especial sus formas de gestión colectiva), asociada, mixta, la propiedad estatal o el acceso mismo a las distintísimas formas de propiedad derivadas de las relaciones laborales o de economía solidaria, la propiedad (algunos hablan de la riqueza generada de) derivada de la indemnización por dańos, los subrogados pecuniarios en todas las áreas del derecho de responsabilidad: minero, medioambiental, bursátil, solo por mencionar algunas áreas jurídicas al azar, la garantía de supervivencia de las comunidades con concepciones del mundo diversas, como los indígenas o las negritudes, la justa explotación del intelecto y de los recursos patrimoniales, la verdadera riqueza agraria y ganadera son (siguen siendo) en las 
Sin embargo, para ser preciso, aún no se han propiciado en Colombia ulteriores desarrollos en el entendimiento de la propiedad, como la necesidad de garantizarla constitucional y legalmente, con la carga de la utilidad para todos y del bien común, como sí ocurre en el derecho comparado. La regulación minuciosa de las diferenciaciones entre la propiedad privada, empresarial y financiera, frente a la propiedad del individuo; las regulaciones de la propiedad sobre el territorio y los recursos naturales o sobre los grandes medios de comunicación, son precarias aún, así como las aplicaciones constitucionales del derecho de propiedad colectiva, comunitaria y sobre todo cooperativa. La redefinición de la propiedad de las transnacionales, en términos tributarios y de inversión, tampoco ha sido desarrollada. Tan solo al mencionar este listado ad libitum resulta claro por qué en Colombia el derecho de propiedad se ha concebido como el más importante y además como el derecho que permite reconocer a los más fuertes. La gran dicotomía jurídica latinoamericana implicó que los más ricos debían "ajustarse jurídicamente" para conservar lo adquirido, en tanto los desposeídos debían luchar por lo que sistemáticamente les había sido negado. La propiedad (de la tierra), por supuesto, significó en algún punto la coyuntura definitiva para la verdadera inclusión social (Pisarello y Tedeschi, 2011, pp. 128-129).

A estas alturas, el lector, y en general quien tenga acceso a estas ideas se estará preguntando: ¿para qué reivindicar el trasfondo marxista de un autor de las calidades de Valencia Zea, en un mundo capitalista actual? Aclaro que, aunque simpatizo con las ideas socialdemócratas, no soy marxista. Al respecto, una única respuesta debería bastar: por un apego a la verdad científica, pero si ello no fuera suficiente, habría, en gracia de discusión, muchas más razones: porque lo que el mundo ha vivido desde el 2008 es una forma de notificación en cuotas, una premonición de la necesidad de modificar el capitalismo. El 95\% de la riqueza está concentrada en menos del 3\% de la población. Los indignados, la imposibilidad de la recuperación plena de la Zona Euro (Castro, 2014, pp. 81-104), la crisis norteamericana, el mundo del capital globalizado. A pesar de imaginarios atolondrados como los de Francis Fukuyama, se

socialdemocracias desarrolladas el derecho extraconstitucional más importante y la única forma de posibilitar la paz jurídica. Valencia Zea desde su vanguardismo multidisciplinar se hizo consciente de ello, de manera muy temprana para su época. No habrá paz en una sociedad extremadamente desigual en términos patrimoniales y este es el legado de Valencia Zea, quien de alguna manera focaliza sus estudios en la posesión y la propiedad, como mecanismos, y como ha quedado visto. Confrontar entre muchos otros a Hattenhauer o a Medicus (Hattenhauer, 1982, pp. 125-129) (Medicus y Petersen, 2011, pp. 209-292). 
reavivan los conflictos en todo el mundo, lamentablemente y en una mayor medida, por la imposibilidad de eliminar la pobreza, de brindar recursos a todos los habitantes del planeta, no por un impedimento físico en sí o por déficit de alimentos, sino por una perversión del sistema capitalista mismo, en el que muy pocos tienen demasiado y muchísimos no tienen prácticamente nada (Marx, 2009, pp. 81-93). El acceso al recurso hídrico ha comenzado a ser un punto en las agendas políticas, los desahuciados españoles, los ofendidos del fútbol en Brasil, la imposibilidad de acceso a Ucrania, el fortalecimiento militar y peligroso de una Rusia impredecible, sedienta casi tanto como los Estados Unidos de América, de combustibles fósiles; la demanda de recursos por parte de la cada día más poderosa República Popular China, la lista podría ser interminable ${ }^{45}$.

El giro ecológico de la izquierda, los partidos verdes en todo el mundo han encontrado un creciente eco, ante la fragilidad del planeta (Altvater, 2006, pp. 341-360). Hay un conflicto entre la necesidad de dar marcha atrás o de por lo menos controlar el impacto de nuestra forma económica sobre la biósfera. Los imperativos de un mercado capitalista parecen acallar reiterativamente las más evidentes demandas de disminución de la polución. Ya no China, sino Francia sufrió en el 2013 la peor tormenta de $\mathrm{CO}_{2}$ de toda la historia de Europa: máximo crecimiento continuado en busca de beneficios. Este es el talón de Aquiles del capitalismo. Actualmente no podemos saber cuál será la flecha mortal, pero no es difícil imaginar que el calentamiento global empieza a pasarnos su factura ${ }^{46}$.

Resulta perverso que se hagan relecturas minimizadoras de grandes pensadores, máxime si se contextualiza la situación social de nuestro país, donde durante todo el

45 Como bien lo postulan Attali y Hobsbawm, Marx continúa siendo una enorme fuerza en tres aspectos: como pensador económico, como historiador y analista, y como el reconocido padre fundador (junto con Durkheim y Max Weber) del pensamiento moderno sobre la sociedad. Claramente lo que no dejó de tener suma importancia fue su visión sobre el capitalismo como una modalidad históricamente temporal de la economía humana y su análisis de este, siempre en expansión y concentración, generando crisis y autotransformándose (Hobsbawm, 2011, p. 21)

46 La grandeza de Marx, como escribe Attali, es que "los filósofos anteriores a él pensaron en el hombre en su totalidad, pero él fue el primero en aprehender el mundo en su conjunto, que es a la vez político, económico, científico y filosófico". Por supuesto, hay muchas partes de su trabajo que son obsoletas, pero nadie lo va a dogmatizar hoy en día, como no se dogmatizó, tras el paso del tiempo y el asentamiento firme de sus ideas a Kant, a Fichte o a Berkeley. 
siglo xx y aún hoy mueren niños de hambre, donde el desplazamiento por el conflicto armado es tan alto como en Siria, actualmente en guerra, donde el coeficiente de Giny es el más atentatorio del ciudadano, luego de Brasil y Haití en todas las Américas. Promover una lectura formalista, un tanto pueril de un pensamiento tan vanguardista y revolucionario como el de Valencia Zea, es claramente desproporcionado y en alguna medida peligroso en términos de rigurosidad en las ciencias sociales.

La solución del siglo xxi es volver a hacer las mismas preguntas de Marx, aunque no se acepten las respuestas ofrecidas por sus discípulos políticos. No ocurre lo propio con sus discípulos historiadores, economistas y hasta juristas, como lo pone de presente, por encima de cualquier otro buen ejemplo, el caso de Valencia Zea.

Tal vez Valencia en sus inicios haya sido inquieto, en el sentido de jurista, émulo de lo francés; tal vez lo haya cautivado Kelsen, aunque en realidad lo dudo demasiado, pero esa discusión es la menos significativa, de todas las susceptibles de proponer sobre la obra de Valencia Zea. Una lectura teórica de Valencia Zea solo puede ser funcionalista y sociológica, como lo he postulado, y debe permitir reconocer que su dogmática privatista, agotadora y rigurosa fue un proemio a una propuesta de mucho mayor calado: el mejor entendimiento de la posesión y de la propiedad como institutos al servicio de Latinoamérica, pero por sobre todo de la humanidad entera, no de unos cuantos; si es que debemos aún atender al concepto de "glocalización" que crea, postula y desarrolla inteligentemente Ulrich Beck.

Probablemente Valencia Zea fue como pocos, un jurista forjador del futuro de este país, pero por encima de cualquiera de esos calificativos, él, además de rigurosos juristas, nos hizo a cientos de miles de estudiosos de sus libros, seres humanos más conscientes de lo jurídico, más sensibles a nuestra realidad y por sobre todo más libres; en una fantástica lectura reivindicatoria del derecho, mas no emancipatoria, para recordar el juicioso sentido propuesto por Mejía Quintana (2013, pp. 147-148).

Valencia Zea propone un capitalismo racional y democrático que permita la consolidación de un ethos pacífico, en una sociedad más igualitaria, menos excluyente, en términos de distribución de la riqueza; como ocurrió y ocurre en las socialdemocracias nórdicas, que por vía de la República Federal de Alemania, Valencia Zea bien 


\section{conoció y estudió ${ }^{47}$. Sin embargo, Valencia Zea, por lo demás, dogmático riguro-}

$47 \mathrm{Al}$ respecto, las sucesivas ediciones, p. ej. entre otros, de Jörn Ipsen, sobre derechos fundamentales, articulan debidamente el entendimiento del estado de la jurisprudencia sobre el derecho a acceder al Daseinsvorsorge, esto es, al derecho a una asistencia social plena, como derecho derivado, de forma mediata, de la garantía constitucional del derecho a la propiedad. Valencia Zea, por supuesto, tuvo algún grado de conocimiento al respecto.

Esos desarrollos se derivan del inciso segundo del artículo 14 de la Ley Fundamental, así: "El estado social moderno ha asumido la previsión de asistencia social, para imprevistos de vida, enfermedad, accidente, ancianidad, para un círculo amplio de la población. Si se toma como núcleo de la garantía de la propiedad, el aseguramiento de la existencia [confrontar las decisiones BVerfGE 69, 272 (300); 72, 9 (19); esto es haciendo prevalecer esa visión en la protección jurídico constitucional de la propiedad] se quiere entonces, consecuentemente, postular (ese derecho) como pretensión de derecho público a subordinar en el área de protección de los derechos fundamentales. De otro lado, también es una postulación del principio del estado social, que, sin embargo, de acuerdo a la opinión general, solo ha querido garantizar un mínimo vital (Existenzminimum). [Cfr. BVerfGE 82, 60(80)]. Ya que para el sector social, los medios de financiación necesarios no son constantes, sino que (en primer lugar: depende de los tributos)", y he allí la conexidad con la garantía de la propiedad, "depende de los ingresos del estado, está por lo demás y por consiguiente excluido, que las pretensiones a prestaciones, se entiendan garantizadas constitucionalmente a su nivel más alto. Ya que, de acuerdo a las más novedosas jurisprudencias del Tribunal Constitucional Federal, el Artículo 14 de la Ley Fundamental, impone el direccionamiento, sobre estos límites, [Cfr. BVerfGE 93, 121, (138); 115, 97, (113f.)], se llegaría (si la situación fuera diversa) al resultado paradójico de que ese mismo derecho, de un lado, impusiera pretensiones jurídico constitucionales; y, de otro lado, sin embargo, le contrapusiera el aprovisionamiento de los medios financieros necesarios para la asistencia social correspondiente. Como punto de fuga y solución para semejante dilema, piensa la doctrina mayoritaria, que dependerá de si las pretensiones por prestaciones positivas, en contra del estado, a través de las propias prestaciones (esto es la propiedad del ciudadano petente), podrían ser resueltas y fundamentadas, en la parte esencial del respectivo derecho.[ Cfr. BVerfGE 45, 142 (170); 48, 403, (413); 53, 257, (291 f.) entre otras decisiones]. En la razón última de la más reciente decisión del Tribunal Constitucional Federal, se menciona, por lo demás:

"Presupuesto para una protección de posiciones jurídicas derivadas de un seguro social, derivado de una garantía a la propiedad, es la demostración de una posición jurídica de valores patrimoniales, que ha de subordinarse de acuerdo a la clase de derecho de exclusividad del titular del derecho, como aprovechable en términos privados. Esa subordinación disfruta de la protección de la garantía de la propiedad, si ella no afecta prestaciones propias y significativas del asegurado y para ello sirve la existencia del seguro. Si no se reúnen esos presupuestos, entonces, entran en consideración, eventuales afectaciones legales en las posiciones jurídicas del petente del seguro social; o, concretamente una protección a través de otros derechos fundamentales, mas no las protecciones derivadas del artículo 14 de la Ley Fundamental. Una protección que se derive y se consolide sobre ello, a través de la garantía de propiedad, no se justificaría más, de acuerdo a la visión completa (sistemática) de la constitución, para los certeros fines de sus funciones" [Así, la sentencia BVerfGE 69, 272, (300)]”. (Ipsen, 2013, p. 210). La traducción es mía.

Estas consideraciones, como se dijo, se derivan del inciso segundo del artículo 14 de la Ley Fundamental alemana. Al efecto, se transcribe el artículo respectivo de manera completa:

"Artículo 14. [Propiedad, derecho a la herencia y expropiación].

(1) La propiedad y el derecho a la herencia están garantizados. Su contenido y sus límites serán determinados por las leyes.

(2) La propiedad obliga. Su uso debe servir al mismo tiempo al bien común.

(3) La expropiación está permitida sólo por razones de bien común. Podrá ser efectuada sólo por ley o en virtud de una ley que establezca el modo y el monto de la indemnización. La indemnización se fijará considerando 
so, era muy consciente de las capacidades meramente reivindicativas del derecho objetivo; la parte propositiva de su obra así lo evidencia. A pesar de ser marxista, nunca le otorgaría una capacidad emancipatoria, revolucionaria o reformista a lo jurídico, como algunas opciones interpretativas, demasiado inocentes, lo promueven (De Sousa, 2011, p. 55 y ss.). Nunca cayó en las tentaciones teorizadoras, vacuas, peligrosas e inútiles.

\section{ConClusiones}

Una primera conclusión es que juzgar la obra de Valencia Zea desde Geny, desde el acogimiento de las tesis renovadoras de la Corte dorada del 36 y desde una mala lectura de Kelsen ${ }^{48}$ es un despropósito ${ }^{49}$. No es adecuado afirmar oclusiva y perentoriamente, una y otra vez, que Valencia Zea fue un simple lector de los juristas inquietos y de Kelsen entre el 45 y el 57. Esa apreciación resulta demasiado ligera. Valencia Zea diría que semejante percepción no acompasaría con la teleología de su tratado y de sus obras propositivas.

Una segunda conclusión tiene que ver con el hecho de que la teoría jurídica, como traté de hacerlo ver aquí, es mucho más que idear recursos discursivos. La teoría jurídica es, tal vez, como lo menciona adecuadamente el profesor Bernd Rüthers, la tarea jurídica más exigente y compleja. Es por ello quizá que, como él lo afirmaba con razón, el mejor teórico del derecho es aquel que ha sido profesor, litigante y juez. Las teorías vacuas, artificiosas, pueden tornarse antojadizas, pero además invasivas

en forma equitativa los intereses de la comunidad y de los afectados. En caso de discrepancia sobre el monto de la indemnización quedará abierta la vía judicial ante los tribunales ordinarios”.

48 Pero además una precisión certera, a esta altura, es que tampoco Kelsen estaría conforme en que se le adjudicase como epígono a un marxista reformista estatal, como bien hubiese categorizado el mismo Kelsen a Valencia Zea; pues sus críticas al respecto son harto conocidas. Kelsen, además de criticar a Stucka, a Rejsner, a Pashukanis y a Vishinsky, toma comprensible distancia con todas las obras teórico-jurídicas basadas en cualquier forma de materialismo histórico o dialéctico; pero más aún, el primer Kelsen, que López trata de incrustar en la obra de Valencia Zea, prescinde de la posibilidad de analizar lo jurídico desde cualquier clase de ideología. Al respecto, ver Ruiz Manero, en su resumida y agradable ponencia sobre el punto (2006, p. 123 y ss.).

49 Eso, sería tanto como juzgar la obra de López desde las “inciertas musitaciones hartianas" escritas en la Universidad Javeriana (López, 2004, p. 8) y, por supuesto, a lo mejor, por sobre todo el mismo López, no estaría de acuerdo con esa lectura histórica minimalista de su trabajo. 
y perversas, en la medida en que crean una "no lectura" en el estudiantado, que no corresponde para nada con la verdadera ciencia. El hermeneuta, por lo menos jurídicamente, hoy en día, no puede ser más que el texto. La obra de Valencia Zea se encuentra completamente vigente, viva y fuerte en todos los salones de clase de las facultades de derecho y filosofía de este país, pero también en cada despacho judicial que se precie de ser serio. Por sobre todo, la obra de Valencia Zea se encuentra completa y nos enseña a aprender de nuestra propia historia, como bien lo postula Habermas (2006, pp. 43 y ss. y 176 y ss.), de donde se sigue, entre otras cosas, que es necesario hacer reconstrucciones iusteóricas responsables.

La idea de esta ponencia es avivar la teoría jurídica seria y, en consecuencia, por lo pronto la respetuosa invitación es — como lo ordenan los cánones de la ciencia— a replicar este texto, a corregirlo, a criticarlo duramente y, por supuesto, a rebatirlo, solo así se construye la verdadera ciencia y solo así podemos crear percepciones certeras en nuestros estudiantes. Considero que tachar de inquieto, positivista, de alguna manera de formalista miope, a un marxista ejemplar, pero por sobre todo a un jurista riguroso, que a fuerza de repensar la problemática social, se volvió un visionario, es un verdadero sacrilegio científico.

Por último, quisiera recordar cómo, al final de uno de sus más bellos escritos, $E l$ elogio de Santo Tomás, Umberto Eco se pregunta y especula sobre qué haría el gran Tomás si viviera hoy en día entre nosotros. Eco lo propone imaginativo, revolucionario y filósofo, comentando a Freud y a Marx, la física relativista, la lógica formal, comentando el existencialismo y la fenomenología. Cambiaría el método argumentativo, que sería menos armónico, introduciría la provisionalidad histórica. Por supuesto sería bueno, pero posiblemente no sería cristiano y nos enseñaría a pensar limpiamente. Sin pretender ponerme en esa categoría de altísimo pensamiento contemporáneo, la tentación de identificar la descripción de Eco con Valencia Zea se antoja propicia. Pero aún más: si se prolongara el mismo ejercicio con Valencia Zea hasta el año 2014 — centenario de su nacimiento- deberíamos advertir que Valencia Zea seguiría siendo un jurista visionario, un adelantado a su época, alguien que ya hubiese articulado verdaderamente el derecho privado y el derecho constitucional derivado del texto de 1991 y en especial el dinamismo de la propiedad, consiguiendo a través de la doctrina, como fuente auxiliar del derecho, que todos los asociados de 
Colombia pudiésemos garantizarnos un mínimo vital "propio", pero también necesario y justo, para nuestro vital y normal desarrollo, como ha comenzado a ocurrir en Uruguay, Ecuador, Chile o Brasil. Crítico implacable, en sus análisis de los fallos de toda nuestra jurisdicción, habría contribuido a reorganizar — de verdad - el caos jurisprudencial que hoy en día vivimos. Pero, retornando a la realidad, como nos pasa con Tomasso, aún hoy seguiremos nutriéndonos de las agudas ideas y portentosos constructos dogmáticos del gran profesor Arturo Valencia Zea: el maestro por antonomasia. Su visión social y crítica es y será un faro que guíe esa creatividad jurídica, ese repensar las instituciones, para adaptar y crear, que tanto promovió en la Nota preliminar de todas las ediciones de su primer y eterno tomo.

\section{REFERENCIAS}

Acosta, M. (2008). Tragedia, política e historia: una lectura de la filosofía hegeliana de juventud. En M. Acosta, J. Díaz (Eds.), La nostalgia de lo absoluto: pensar a Hegel hoy. Bogotá, Colombia: Universidad Nacional de Colombia. Facultad de Ciencias Humanas.

Agudelo, C. (2012). La tesis de Arturo Valencia Zea de 1941: interpretación de la ley y fuentes del derecho a la luz de F. Gény y el clasicismo jurídico local. En H. Alviar García (Coord.), Perspectivas contemporáneas en la investigación jurídica. Bogotá, Colombia: Universidad de los Andes, Ediciones Uniandes.

Altvater, E. (2006). ¿Existe un marxismo ecológico? En Boron, Amadeo, González (Comp.), La teoría marxista hoy. Problemas y perspectivas. Buenos Aires, Argentina: Colección, Campus virtual. Recuperable bajo: http://bibliotecavirtual.clacso.org.ar/ar/libros/campus/marxis/marxis.pdf (Fecha de última descarga: 15 de junio de 2014).

Alviar García, H., Villegas del Castillo, C. (2012). La función social de la propiedad en las constituciones colombianas. Bogotá, Colombia: Universidad de los Andes, Ediciones Uniandes.

Aricó, J. (2010). Marx y América Latina. Buenos Aires, Argentina: Fondo de Cultura Económica de Argentina S.A.

Attali, J. (2007). Karl Marx o el espiritu del mundo. Buenos Aires, Argentina: Fondo de Cultura Económica de Argentina S.A. (Trad. Goldstein V.). 
Benjamín, W. (2001). Ensayos escogidos. México D.F., México: Filosofía y Cultura Contemporánea, ediciones Coyoacán. (Trad. Murena H. A.).

Bobbio, N. (1999). Marx y la teoría jurídica. En N. Bobbio, Ni con Marx ni contra Marx. México D. F., México: Fondo de Cultura Económica.

Bucher, E. (2001). Zu Europa gehört auch Lateinamerika! Siehe unten die Webseite: ZEuP, http://www.eugenbucher.ch/pdf_files/91.pdf (Fecha de última descarga: 15 de junio de 2014).

Carrillo, R. (1947/1979). Ambiente axiológico de la teoría pura del derecho. Bogotá, Colombia: Universidad Nacional de Colombia - Carlos Valencia Editores.

Castro, G. (2013). Das Pactum de Contrahendo - Der Vorvertrag -. Möglichkeiten einer europäischen Rechtsvereinheitlichung auf der Basis eines Rechtsvergleichs der deutschen und französischen Rechtsordnungen. Konstanz, Baden-Wurtemberg, Bundesrepublik Deutschland: Hartung-Gorre Verlag.

Castro, G. (2014). El euro y el consumidor como fenómenos políticos en el actual desarrollo de Europa. Apuntes del Centro de Estudios Económicos 56 Vol. 32 Julio-Diciembre de 2013. Tunja, Colombia: Universidad Pedagógica y Tecnológica de Colombia.

Código Judicial. (1966). Código Judicial. Bogotá D.E., Colombia: Editorial Voluntad, Colección Codex Brevis, dir. Arcadio Plazas.

De Sousa, B. (2008). Reinventar la democracia reinventar el Estado. Madrid, España: Ediciones Sequitur. (Trad. Eraso J.).

Frankenberg, G. (2011). Teoría crítica. Academia. Revista sobre enseñanza del derecho. Año 9, Vol. 17. Buenos Aires, Argentina: Recuperable bajo: http://www.derecho.uba.ar/publicaciones/rev_academia/revistas/17/teoria-critica.pdf. (Fecha de última descarga: 15 de junio de 2014).

Garaudy, R. (1966). Metodología del marxismo. En Lecciones de filosofía Marxista. México D.F., México: Juan Grijalbo Editor. Colección, Ciencias Económicas y Sociales.

Geny, F. (1925). Método de interpretación y fuentes en derecho privado positivo. Madrid, España: Editorial Reus S.A. 
Giorgi, R. (1976). Zur Kritik der sogenannten marxistischen Rechtstheorie. Ed. Nomos. Recuperable bajo: http://www.kj.nomos.de/fileadmin/kj/doc/1976/19763de_Giorgi_S_271. pdf. (Fecha de última descarga: 15 de junio de 2014).

Gomez, B. (s.f.). Desarrollo del pensamiento jurídico colombiano, desarrollo y recepción contemporánea del derecho civil en Colombia, siglos XIX y XX en informes de investigación, grupo pedagogía y derecho. Recuperable bajo: dialnet.unirioja.es/descarga/articulo/1706967.pdf. (Fecha de última descarga: 15 de junio de 2014).

Gómez, J. (1981). Bienes. Bogotá, Colombia: Universidad Externado de Colombia. (Actualizado por Bernal D.).

Gómez, J. (1963). Régimen de tierras. Suplemento de las conferencias de derecho civil II. Bogotá, Colombia: Publicaciones de la Universidad Externado de Colombia.

Habermas, J. (1998). Más allá del Estado nacional. México D.F., México: Fondo de Cultura Económica. (Trad. Jiménez M.).

Hattenhauer, H. (1987). Conceptos fundamentales del derecho civil. Barcelona, España: Ariel Derecho. (Trad. Hernández G.).

Hegel, G. (1944). Filosofia del derecho. Buenos Aires, Argentina: Editorial Claridad. (Trad. Mendoza A.).

Hegel, G. (1983). Introducción a la historia de la filosofía. Madrid, España: Sarpe. (Trad. Terrón E.).

Hobsbawm, E. (2011). Cómo cambiar el mundo. Marx y el marxismo 1840-2011. Barcelona, España: Crítica. (Trad. Furió S.).

Ihering, R. (1926). La posesión. Madrid, España: Editorial Reus S.A. (Trad. Posada A.).

Ipsen, J. (2013). Staatsrecht II. Grundrechte. 16. Auflage, Munich, Alemania: Verlag Franz Vahlen.

Jaramillo, R. (1982). Introducción de la filosofía moderna en Colombia. Revista Argumentos Universidad y Sociedad No. 14/15-16/17. Bogotá, Colombia: Fundación Editorial Argumentos.

Kalmanovitz, S., López, E. (2006). La agricultura colombiana en el siglo XX. Bogotá, Colombia: Fondo de Cultura Económica, Banco de la República. 
Kelsen, H. (2009). El método y los conceptos fundamentales de la teoría pura del derecho. Madrid, España: Editorial Reus S.A. (Trad. López J.).

Kennedy, D. (2010). Izquierda y derecho. Ensayos de teoría jurídica crítica. Buenos Aires, Argentina: Siglo Veintiuno Editores. (Trad. Moro G.).

Larenz, K. (1994). Metodología de la ciencia del derecho. Barcelona, España: Ariel Derecho. (Trad. Editorial Planeta S.A.).

Latorre, L. (1937). Doce leyes y otros trabajos parlamentarios. Bogotá, Colombia: Editorial Minerva S.A.

López, D. (2004). Teoría impura del derecho. Bogotá, Colombia: Legis editores.

Marx, C. (1999). El capital: crítica de la economía politica, II. México D. F., México: Fondo de Cultura Económica. (Trad. Roces W.).

Marx, K. (2009). Las crisis del capitalismo. Madrid, España: Ediciones Sequitur. (Trad. Nadal A.).

Medicus, D., Petersen, J. (2011). Bürgerliches Recht, Eine nach Anspruchsgrundlagen geordnete Darstellung zur Examensvorbereitung. Munich, Alemania: Verlag Franz Vahlen.

Mejía, O. (1997). Derecho, legitimidad y democracia: desarrollo y conflicto de los paradigmas jurídicos en Colombia. Revista Pensamiento Jurídico No. 8. Bogotá, Colombia: Unibiblos, Universidad Nacional de Colombia.

Mejía, O. (2013). Derecho, alienación e ideología. ¿Potencialidades emancipadoras del derecho en las sociedades complejas? Bogotá D. C., Colombia: Grupo Editorial Ibáñez.

Mejía, O. (2013a). Habermas: lectura heterodoxa de Marx. En J. Quiñones (Ed.), Repensar a Marx hoy. Bogotá D.C., Colombia: Universidad Nacional de Colombia, Instituto Unidad de Investigaciones jurídico-sociales "Gerardo Molina” (Unijus).

Ortega, J. (1979). Código Civil. Bogotá, Colombia: Editorial Temis.

Pisarello, G., Tedeschi, S. (2011). Propiedad y Constitución en la Argentina: del "derecho terrible" a la democracia económica. En R. Gargarella (Comp.), La Constitución en 2020: 48 propuestas para una sociedad igualitaria. Buenos Aires, Argentina: Siglo Veintiuno Editores. 
Raz, J., Alexy, R., Bulygin, E. (Trads.) (2007). Una discusión sobre la teoría del derecho. Madrid - Barcelona, España: Marcial Pons, Ediciones Jurídicas y Sociales S.A.

Reich, N. (1973). Marxistische Rechtstheorie. Historische und aktuelle Diskussionen und Tendenzen. Tübingen, Baden-Württemberg, Bundesrepublik Deutschland: J.C.B. Mohr Paul Siebeck.

Ruiz, J. (2006). Sobre la crítica de Kelsen al Marxismo. En O. Correas (Comp.), El otro Kelsen. México D.F., México: Instituto de investigaciones Jurídicas de la UnAm y ediciones Coyoacán.

Rüthers, B., Fischer, C., Birk, A. (2013). Rechtstherorie mit Juristischer Methodenlehre. Munich, Alemania: Verlag C. H. Beck.

Sierra, R. (1978). Ensayos filosóficos. Bogotá, Colombia: Instituto Colombiano de Cultura, Editorial Andes, Colección Autores Nacionales.

Somarriva, M. (1983). Evolución del código civil chileno. Bogotá, Colombia: Editorial Temis.

Stammler, R. (2011). Economía y derecho según la concepción materialista de la historia. Una investigación filosófico-social. Madrid, España: Editorial Reus. (Trad. Roces W.).

Stammler, R. (2011a). La teoría crítica del derecho. México D.F., México: Ediciones Coyoacán S. A. de C. V. (Trad. Bremer J. J.).

Valencia, A. (1957). Derecho civil. Tomo I, Parte general y personas. Bogotá, Colombia: Editorial Temis.

Valencia, A. (1958). Derecho civil. Tomo II, Derechos reales. Bogotá, Colombia: Editorial Temis.

Valencia, A. (1974). Derecho civil. Tomo III, De las obligaciones. Bogotá, Colombia: Editorial Temis.

Valencia, A. (1978). La posesión. Bogotá D. E., Colombia: Editorial Temis.

Valencia, A. (1980). Proyecto de código de derecho privado. Bogotá, D.C., Colombia: Superintendencia de Notariado y Registro.

Valencia, A. (1982). Origen, desarrollo y crítica de la propiedad privada. Bogotá, Colombia: Editorial Temis. 
Valencia, A. (1989). Derecho civil. Tomo I, Parte general y personas. Bogotá, Colombia: Editorial Temis.

Valencia, A. (1990). Derecho civil. Tomo II, Derechos reales. Bogotá, Colombia: Editorial Temis.

Varios autores. (1995). Arturo Valencia Zea, El hombre, el jurista. Santa Fe de Bogotá, Colombia: Editorial Temis.

Zuleta, E. (1974). Estudios jurídicos. Bogotá, Colombia: Editorial Temis. 